\title{
Why Is the Oxidation State of Iron Crucial for the Activity of Heme- Dependent Aldoxime Dehydratase? A QM/MM Study
}

\author{
Rong-Zhen Liao and Walter Thiel* \\ Max-Planck-Institut für Kohlenforschung, Kaiser-Wilhelm-Platz 1, D-45470, Mülheim an der Ruhr, Germany
}

Supporting Information

ABSTRACT: Aldoxime dehydratase is a heme-containing enzyme that utilizes the ferrous rather than the ferric ion to catalyze the synthesis of nitriles by dehydration of the substrate. We report a theoretical study of this enzyme aimed at elucidating its catalytic mechanism and understanding this oxidation state preference $\left(\mathrm{Fe}^{2+}\right.$ versus $\left.\mathrm{Fe}^{3+}\right)$. The uncatalyzed dehydration reaction was modeled by including three and four water molecules to assist in the proton transfer, but the computed barriers were very high at both the DFT

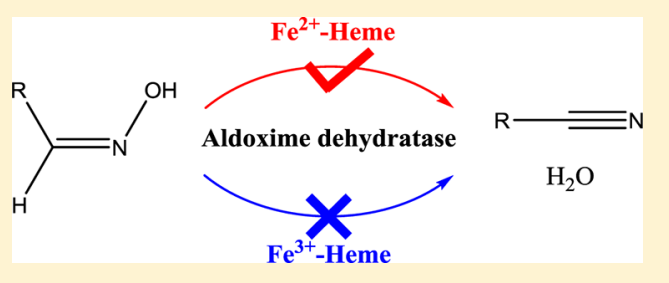
(B3LYP) and coupled cluster CCSD(T) levels. The enzymatic dehydration of $Z$-acetaldoxime was explored through QM/MM calculation using two different QM regions and covering all three possible spin states. The reaction starts by substrate coordination to $\mathrm{Fe}^{2+}$ via its nitrogen atom to form a six-coordinated singlet reactant complex. The ferrous heme catalyzes the $\mathrm{N}-\mathrm{O}$ bond cleavage by transferring one electron to the antibond in the singlet state, while His 320 functions as a general acid to deliver a proton to the leaving hydroxide, thus facilitating its departure. The key intermediate is identified as an $\mathrm{Fe}^{\mathrm{III}}\left(\mathrm{CH}_{3} \mathrm{CH}=\mathrm{N}^{\bullet}\right)$ species (triplet or open-shell singlet), with the closed-shell singlet $\mathrm{Fe}^{\mathrm{II}}\left(\mathrm{CH}_{3} \mathrm{CH}=\mathrm{N}^{+}\right)$being about $6 \mathrm{kcal} / \mathrm{mol}$ higher. Subsequently, the same His 320 residue abstracts the $\alpha$-proton, coupled with electron transfer back to the iron center. Both steps are calculated to have feasible barriers $(14-15 \mathrm{kcal} / \mathrm{mol})$, in agreement with experimental kinetic studies. For the same mode of substrate coordination, the ferric heme does not catalyze the $\mathrm{N}-\mathrm{O}$ bond cleavage, because the reaction is endothermic by about $40 \mathrm{kcal} / \mathrm{mol}$, mainly due to the energetic penalty for oxidizing the ferric heme. The alternative binding option, in which the anionic aldoxime coordinates to the ferric ion via its oxyanion, also results in a high barrier (around $30 \mathrm{kcal} / \mathrm{mol}$ ), mainly because of the large endothermicity associated with the generation of a suitable base (neutral His320) for proton abstraction.

\section{INTRODUCTION}

Aldoxime dehydratase $(\mathrm{Oxd})$ is a heme-containing enzyme that catalyzes the dehydration of aldoximes to form nitriles (Scheme $1),{ }^{1-4}$ which are important intermediates in the industrial

Scheme 1. Reaction Catalyzed by Aldoxime Dehydratase $(\mathrm{Oxd})^{1-4}$

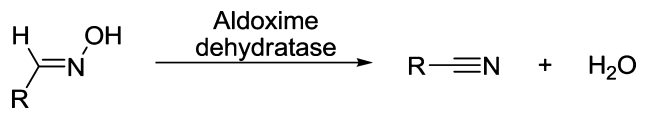

synthesis of nylon, acrylic fibers, and insecticides as well as pharmaceuticals. Many efforts have been devoted to the design of efficient catalytic procedures for aldoxime transformations, focusing on both heterogeneous ${ }^{5-7}$ and homogeneous ${ }^{8-11}$ catalysts. The biological dehydration of aldoxime catalyzed by Oxd provides an environmentally benign approach to the organic synthesis of nitriles. This heme enzyme is special in that it physiologically functions as a hydrolyase, rather than a monooxygenase as in most organisms. ${ }^{12-14}$ Three members of the Oxd family are registered in the Enzyme Structure Database, namely aliphatic aldoxime dehydratase, ${ }^{15}$ phenylacetaldoxime dehydratase, ${ }^{3}$ and indolyl-3-acetaldoxime dehydratase. ${ }^{16,17}$ All Oxd enzymes purified from different microorganisms exhibit a relatively broad substrate scope, accepting both $\mathrm{E} / \mathrm{Z}$ types of aldoximes with alkyl or aryl substituents. $2,3,15,18-22$

The crystal structures of wild-type Oxd from Rhodococcus sp. $\mathrm{N}-771$ (OxdRE) has been solved both in the substrate free form and in complex with propionaldoxime and butyraldoxime. ${ }^{23}$ OxdRE is a homodimer, with one heme molecule in each monomer, similar to OxdRG found in Rhodococcus globerulus A$4,{ }^{15}$ OxdA in Pseudomonas chlororaphis B23, ${ }^{19}$ and OxdK in Pseudomonas sp. K-9. ${ }^{22}$ These enzymes share more than $75 \%$ amino acid sequence identity, suggesting a conserved reaction mechanism..$^{20,22}$ In the active site of the substrate bound form, the heme iron is ligated to $\mathrm{N}^{\delta 1}$ of His 299 and to the $\mathrm{N}$ atom of aldoxime, forming a six-coordinated species. The coordination of His299 appears to be essential since its mutation to alanine in OxdA leads to the loss of the ability to bind heme, thus becoming inactive. ${ }^{24}$ The hydroxyl group of aldoxime forms two hydrogen bonds to the side chains of Ser219 and His320, which help control the substrate orientation. His 320 is further hydrogenbonded to Glu143, which forms a salt bridge with Arg178. The mutagenesis of His320, Ser219, Glu143, and Arg178 leads to

Received: June 5, 2012

Revised: July 10, 2012

Published: July 16, 2012 
Scheme 2. Suggested Reaction Mechanism of Aldoxime Dehydratase ${ }^{32}$
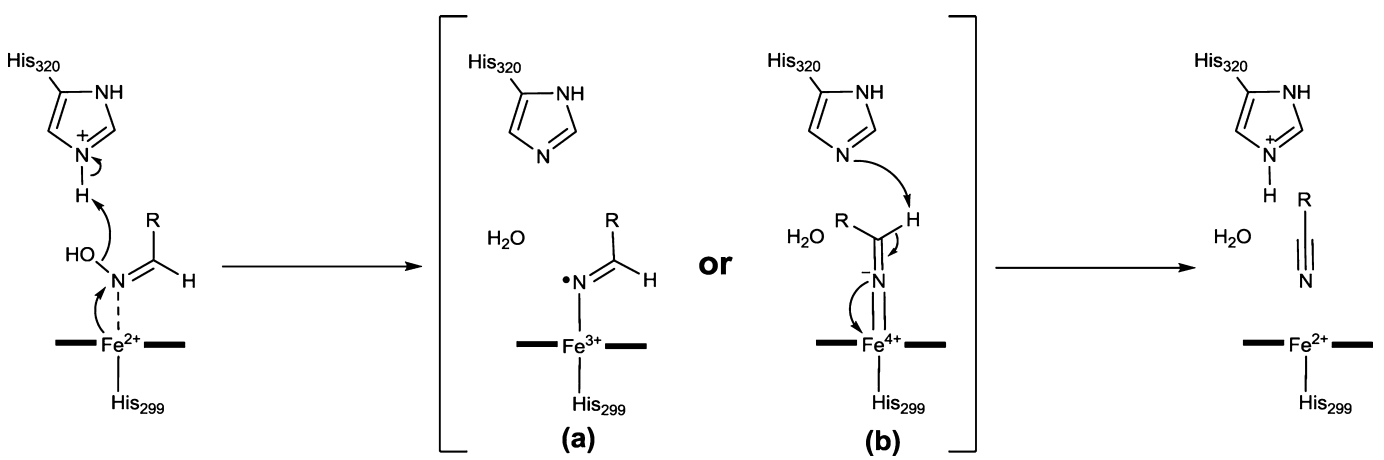

diminished activity, indicating a potential role of these residues in the reaction. $^{23}$

On the basis of kinetic, UV spectroscopic, and ${ }^{1} \mathrm{H}$ NMR studies, Mansuy and co-workers have suggested a reaction mechanism for cytochrome $\mathrm{P} 450$ as well as biomimetic iron porphyrins. ${ }^{25,26}$ The substrate aldoxime coordinates to the ferrous ion via its nitrogen atom, followed by water elimination promoted by general acid-base catalysis. The ferric form of the heme has no reactivity, and the aldoxime binds to the ferric ion through its oxygen atoms, presumably as an oxyanion. ${ }^{25}$ A similar binding mode has been suggested for the interaction between microperoxidase- 8 and $N$-hydroxyguanidines, ${ }^{27}$ and for the ironporphyrin-catalyzed oxidation of oximes. ${ }^{28}$ The reduction of the metal from $\mathrm{Fe}$ (III) to $\mathrm{Fe}(\mathrm{II})$ by $\mathrm{NADPH}$ or other reductants is a prerequisite for catalysis. ${ }^{26}$ Interestingly, only $Z$-arylaldoximes can be transformed to the corresponding nitriles, while $E$ arylaldoximes are not dehydrated, ${ }^{25,26}$ possibly because of their weaker coordination ability to the metal arising from steric repulsion between the $\alpha$-substituents of the substrate and the porphyrin ring. The variations of substituents at the porphyrin ring of the biomimetic system showed an increase of catalytic activity when electron-rich substitutions are present, suggesting electron transfer from electron-rich $\mathrm{Fe}(\mathrm{II})$ to the substrate during the reaction, possibly with formation of a ferryl $\mathrm{Fe}^{\mathrm{IV}}=\left(\mathrm{RCH}=\mathrm{N}^{-}\right)$intermediate. $^{26}$

The reaction mechanism for aldoxime dehydratase has been subjected to detailed mechanistic investigation. ${ }^{29-35}$ Resonance Raman spectroscopic analysis suggests that during substrate binding, the heme $\mathrm{Fe}$ (II) changes from the pentacoordinated high-spin (quintet) state to the hexacoordinated low-spin (singlet) state. ${ }^{29,31}$ For ferric Oxd, EPR studies show the ferric ion to be always hexacoordinated, but its spin state evolves from high-spin (sextet) to low-spin (doublet) when substrate is bound. ${ }^{30}$ Thereafter, the distal His 320 delivers a proton to the hydroxyl group of aldoxime, ${ }^{24}$ affording a $\mathrm{Fe}-\left(\mathrm{RCH}=\mathrm{N}^{+}\right)$ species, which undergoes electron transfer to form a Fe ${ }^{\mathrm{III}}$ or $\mathrm{Fe}^{\mathrm{IV}}$ complex (Scheme 2). ${ }^{32}$ On the basis of time-resolved highfrequency resonance Raman spectra, it was suggested that a $\mathrm{Fe}=$ $\mathrm{N}$ double bond may be formed in this key intermediate, ${ }^{32}$ since its $\mathrm{Fe}-\mathrm{N}$ stretching frequency $\left(857 \mathrm{~cm}^{-1}\right)$ is higher than the $\mathrm{Fe}-$ $\mathrm{N}$ single bond frequency $\left(600-750 \mathrm{~cm}^{-1}\right)$ typically found in heme-NO complexes. ${ }^{36-40}$ The newly formed neutral His 320 is a good candidate to act as a general base that can deprotonate the substrate, regenerating a protonated His320 with liberation of nitrile.

Most recently, after the completion of the draft of this paper, Liu and co-workers published a theoretical study on the reaction mechanism of aldoxime dehydratase (with $Z$-propionaldoxime as

substrate) using a combined quantum mechanical/molecular mechanical (QM/MM) approach. ${ }^{41}$ They found a two-step mechanism, in which His320 first delivers a proton to the aldoxime hydroxyl group during the initial $\mathrm{N}-\mathrm{O}$ bond cleavage, affording an open-shell singlet radical $\mathrm{Fe}^{\mathrm{III}}-\mathrm{RCH}=\mathrm{N}^{\bullet}$, and then abstracts a proton from the intermediate to form the nitrile product (Scheme $2 \mathrm{a}$ ). Their study was restricted to the singlet state and the ferrous heme enzyme. ${ }^{41}$ Hence there are a number of intriguing questions that are still open; for example: What is the reactivity of the higher spin states (triplet and quintet) in aldoxime dehydratase? Is multistate reactivity ${ }^{42,43}$ of crucial importance, like in many other heme enzymes? ${ }^{44,45}$ How do the uncatalyzed and catalyzed reactions compare? What is the catalytic efficiency of the enzyme? Which configuration is more reactive, $Z$ - or $E$-aldoxime? What are the differences between the ferrous and the ferric heme ( $\mathrm{Fe}^{\mathrm{II}}$ versus $\mathrm{Fe}^{\mathrm{III}}$ ) with regard to binding mode and mechanism? Why is the ferric heme not active? Here we address these questions using density functional theory (DFT) and QM/MM calculations. We consider the dehydration of $Z$ - and $E$-acetaldoxime in the singlet, triplet, and quintet state. The uncatalyzed reaction assisted by three and four water molecules was studied by DFT and coupled cluster methods, as a reference for assessing the proficiency of the enzyme. QM/MM calculations were performed for the whole solvated enzyme using two different QM regions (71 and 103 QM atoms) and covering both the ferrous and ferric form of the heme. In addition, QM-only model calculations were carried out to identify the effects of the protein environment through comparisons with the QM/MM data. The resulting mechanistic scenario is consistent with the available experimental findings and is expected to apply analogously to other types of Oxd enzymes, which possess the same active site as OxdRE.

\section{METHODS}

2.1. System Preparation. The initial coordinates were taken from the X-ray structure of OxdRE from Rhodococcus sp. N-771 complexed with propionaldoxime (PDB code: 3A16, resolution $1.6 \AA) .{ }^{23}$ The dimeric form was used and the missing residues at the $\mathrm{N}$-terminal ( 20 amino acids) were omitted and terminated by $\mathrm{CH}_{3} \mathrm{CO}-$, while the $\mathrm{C}$-terminal was terminated by $-\mathrm{NHCH}_{3}$. An active region for the setup was selected containing the atoms within $35 \AA$ of the iron atom of chain $A$. The protonation states of the titratable residues (His, Asp, and Glu) in this active region were determined on the basis of their $\mathrm{p} K_{\mathrm{a}}$ values obtained via the PROPKA $^{46}$ program and verified by visual inspection of the local hydrogen bond networks. Titratable residues outside the active region were selectively protonated; see Supporting Information 


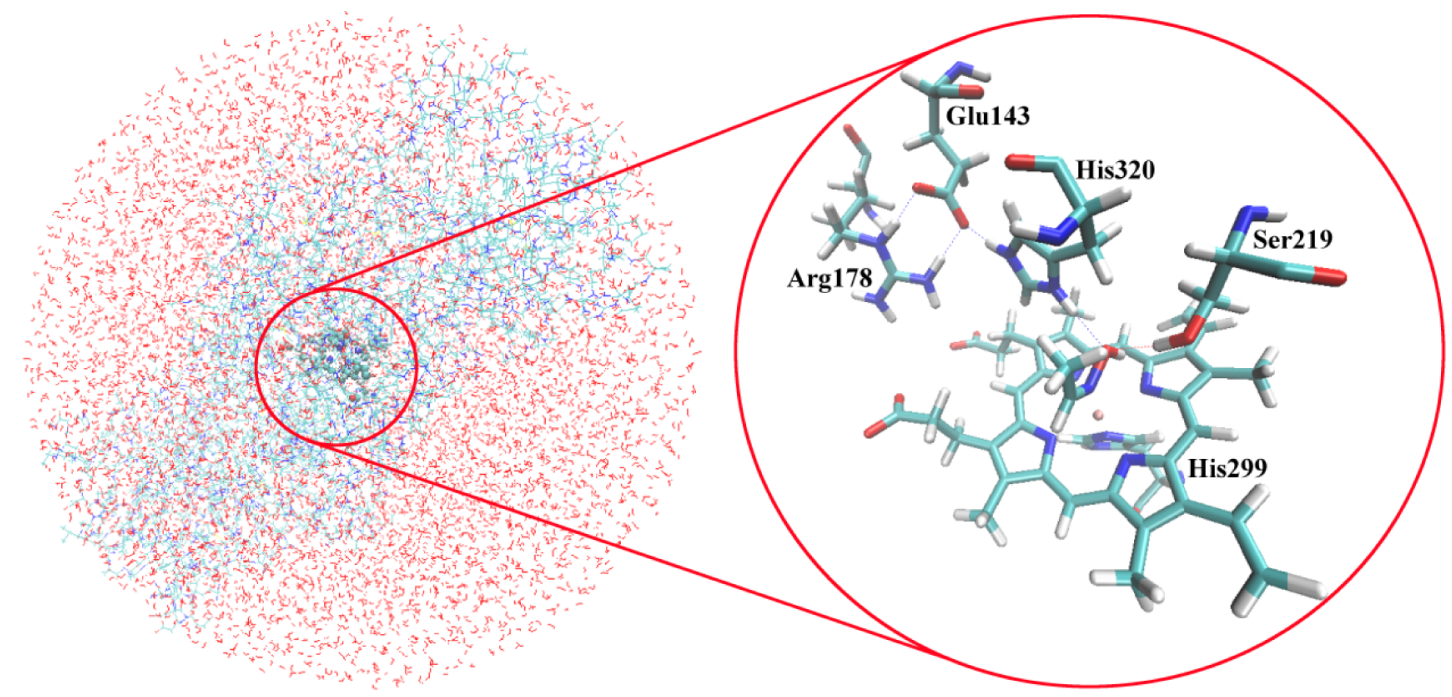

Figure 1. System used in $\mathrm{QM} / \mathrm{MM}$ calculations. The important active-site residues are shown on the right in an enlarged view.

for details. The coordinates of propionaldoxime were used to generate the $Z$-form of acetaldoxime substrate.

The dimeric enzyme was solvated in a water ball of 40 Å radius centered at iron of chain $\mathrm{A}$. Eleven $\mathrm{Mg}^{2+}$ ions were added to neutralize the system via random substitution of solvent water molecules located at least $5.5 \AA$ away from any protein atom. The solvated system was subjected to energy minimization and a 500 ps molecular dynamics (MD) simulation at $300 \mathrm{~K}$ using the CHARMM force field ${ }^{47}$ as implemented in the CHARMM program. ${ }^{48}$ During the simulation, residues more than $35 \AA$ away from the iron atom of chain A were fixed as well as the nonhydrogen atoms of the heme, the ligand His299, and the substrate. The equilibrated system (Figure 1) consisted of 33662 atoms, including 7505 TIP3 water molecules.

To study the $\mathrm{Fe}^{3+}$-catalyzed reaction, the final structure from the initial 500 ps equilibration run was modified (with an aldoxime anion bound to the ferric ion) and then subjected to another 500 ps equilibration run with exactly the same constraints applied as described above for the ferrous OxdRE.

2.2. QM/MM Calculations. The chosen QM/MM methodology is analogous to that used in previous studies from our group, and therefore only some essential features are mentioned here. The final snapshot from the MD trajectories was taken as the starting structure for the QM/MM calculations using the Chemshell software. ${ }^{49,50}$ The TURBOMOLE ${ }^{51}$ program was employed for treating the QM part, while DL_POLY ${ }^{52}$ was used for the MM region represented by the CHARMM force field. The electronic embedding scheme was adopted for the QM region, and hydrogen link atoms with the charge shift model were employed to handle the QM/MM boundary. No electrostatic cutoff was applied for the QM/MM and $\mathrm{MM} / \mathrm{MM}$ interactions. The active region for QM/MM geometry optimization included the QM atoms as well as all residues and water molecules in the MM region within $13 \AA$ of the iron atom of chain A (see Supporting Information for details).

Two different QM regions (71 atoms for M1 and 103 atoms for M2, total charge of +1 ) were chosen for the QM/MM calculations. QM region M1 is composed of the following sets of atoms: iron porphyrin (without heme side chains), the proximal ligand imidazole group of His299 (neutral), the imidazolium group of His 320 (charge of +1 ), the side chain of Ser219 represented by methanol, and the substrate $Z$-acetaldoxime. The larger QM region M2 was selected to allow for a more accurate QM description of the region around the catalytic acid, the protonated His320, by including two neighboring charged residues (Glu143 and Arg178) as well as their hydrogen-bonding partners (two water molecules and the side chain of Ser174).

For geometry optimizations, the QM part was treated by the B3LYP ${ }^{53,54}$ functional using the LANL2TZ(f) ${ }^{55}$ pseudopotential and basis set for Fe, and the 6-31G(d,p) basis for elements $\mathrm{C}, \mathrm{N}$, $\mathrm{O}$, and $\mathrm{H}$ (labeled as BS1). Improved energies were evaluated by performing single-point $\mathrm{QM} / \mathrm{MM}$ calculations using the larger TZVPP basis set. ${ }^{56}$ Empirical dispersion corrections (DFTD2 $)^{57}$ were added to determine the final relative energies. Transition state (TS) optimizations were done with the partitioned rational function optimizer (P-RFO) with Powell update for an explicit Hessian. ${ }^{58}$ Numerical frequency calculations were performed for the core atoms to confirm the nature of the optimized TS (only one imaginary frequency).

2.3. QM-Only Calculations. The QM-only calculations employed the B3LYP functional as implemented in the Gaussian09 program package. ${ }^{59}$ The geometry optimizations utilized the same basis set BS1 as in the QM/MM case. At the optimized geometries, single-point calculations were performed using the larger TZVPP basis set for all atoms. Analytical frequency calculations were carried out at the same level of theory as the geometry optimizations to establish the nature of the various stationary points.

In the spirit of the cluster approach for the modeling of enzymatic reactions, ${ }^{60-62}$ the polarization effects from the protein environment were taken into account by performing single-point calculations at the optimized structures using the SMD continuum solvation model ${ }^{63}(\varepsilon=4)$. The reported QMonly energies for the enzymatic reaction include solvation, zeropoint vibrational, and dispersion corrections.

For the uncatalyzed reaction, single-point calculations were also carried out at the MP2 and coupled cluster (CCSD and $\operatorname{CCSD}(\mathrm{T})$ ) levels. Intrinsic reaction coordinate (IRC) ${ }^{64,65}$ analyses were performed to trace the pathways for the uncatalyzed reaction and to confirm that the optimized TS structures connect the correct reactants and products. The solvation effects from bulk water surrounding the microsolvated substrate were obtained from single-point calculations at the optimized structures using the $\operatorname{SMD}^{63}$ model with $\varepsilon=80$. The 
reported B3LYP energies for the uncatalyzed reaction are Gibbs free energies (without dispersion corrections), which include zero-point vibrational corrections, thermal corrections at $298 \mathrm{~K}$, and solvation free energy corrections. For MP2, CCSD, and $\operatorname{CCSD}(\mathrm{T})$ free energies, these corrections were taken from B3LYP.

\section{RESULTS AND DISCUSSION}

3.1. Uncatalyzed Reaction. To provide a reference for assessing the proficiency of aldoxime dehydratase, we first investigated the uncatalyzed dehydration reaction with the assistance of three and four water molecules. The optimized transition states for both $Z$ - and E-acetaldoxime are shown in Figure 2, and the calculated barriers and reaction energies at various levels are displayed in Table 1.

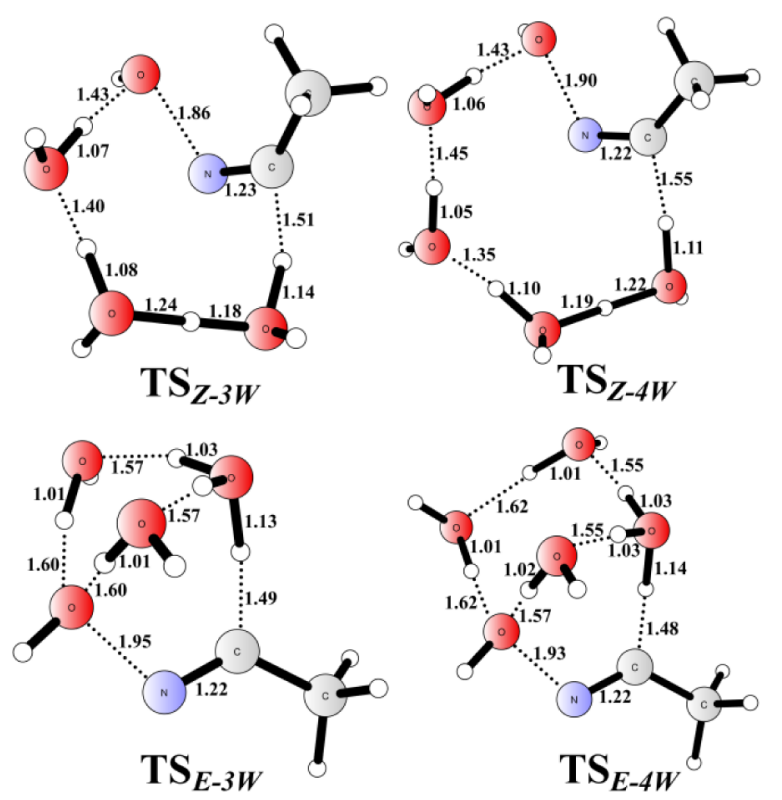

Figure 2. Optimized transition states for dehydration of $Z$ - and $E$ acetaldoxime assisted by three and four water molecules (B3LYP/6$31 G(d, p))$.

Table 1. Calculated Free Energy Barriers and Reaction Free Energies (in $\mathrm{kcal} / \mathrm{mol}$ ) for Dehydration of $Z$ - and $E$ -

Acetaldoxime Assisted by Three and Four Water Molecules at Various Levels

\begin{tabular}{lllrrrc} 
& & & B3LYP & MP2 & CCSD & CCSD(T) \\
3W & Z & barrier & 41.8 & 44.3 & 54.2 & 46.4 \\
& & reaction energy & -43.4 & -49.7 & -45.7 & -44.7 \\
& E & barrier & 42.1 & 47.7 & 53.5 & 46.4 \\
& & reaction energy & -45.4 & -52.8 & -48.4 & -47.8 \\
\multirow{2}{*}{ WW } & Z & barrier & 36.4 & 40.7 & 51.0 & 42.5 \\
& & reaction energy & -45.2 & -50.9 & -46.9 & -45.7 \\
& E & barrier & 36.5 & 44.4 & 50.8 & 43.0 \\
& & reaction energy & -40.3 & -47.3 & -42.8 & -42.2 \\
\hline
\end{tabular}

For $Z$-acetaldoxime, the hydroxy group and the $\alpha$-proton are in trans configuration. This geometric constraint dictates a minimum of three water molecules functioning as a bridge for the proton transfer during water elimination. The reaction takes place in a single concerted step, without the formation of any charge-separated intermediate, as has been confirmed by IRC calculations (see Supporting Information). Table 1 lists the free energy barriers and reaction free energies at various levels. The free energy barrier is calculated to be $46.4 \mathrm{kcal} / \mathrm{mol}$ at the most accurate $\operatorname{CCSD}(\mathrm{T})$ level, and slightly lower values are obtained from MP2 and B3LYP (44.3 and $41.8 \mathrm{kcal} / \mathrm{mol}$, respectively; see Table 1). The reaction is exothermic by more than $40 \mathrm{kcal} / \mathrm{mol}$ at all levels. When an additional water molecule is present (in total four water molecules), the barrier decreases by $4-5 \mathrm{kcal} / \mathrm{mol}$, but still remains very high. Addition of another water molecule (in total five water molecules; see Supporting Information, Table S3 and Figure S3) leads to similar barriers, suggesting little effect by further microsolvation.

Previous theoretical calculations have shown that $E$-acetaldoxime is isoenergetic to $Z$-acetaldoxime and that both isomers have similar chemical potential and hardness. ${ }^{66}$ Transition state optimization of $E$-acetaldoxime surrounded by three water molecules gives a transition structure, in which only two water molecules are involved in the proton transfer, and similar results are found when four or five water molecules are present. The calculated barriers are quite close to those for $Z$-acetaldoxime (Table 1).

The dehydration of pyridine-2-aldoxime methiodide (PAM) has been monitored by UV absorption spectroscopy. ${ }^{67}$ The measured rate constant of $4.53 \times 10^{-5} \mathrm{~min}^{-1}$ at $37^{\circ} \mathrm{C}(\mathrm{pH}=7.1)$ corresponds to a barrier of around $27 \mathrm{kcal} / \mathrm{mol}$ using classical transition state theory. This barrier should be lower than that for dehydration of acetaldoxime since PAM has a cationic $N$-methyl pyridyl group, which can function as a Lewis acid and thus make the deprotonation much easier. The high barriers from the current calculations for the dehydration of acetaldoxime are consistent with the fact that a catalyst is needed to promote this reaction. ${ }^{5-11}$

3.2. $\mathrm{Fe}^{2+}$-Catalyzed Z-Acetaldoxime Dehydration. In this section, we present our QM/MM results for the ferrous Oxd catalyzed $Z$-acetaldoxime dehydration with two different QM regions (71 atoms for $\mathbf{M 1}$ and 103 atoms for $\mathbf{M} 2$, total charge of $+1)$. In addition, an active-site model with exactly the same size as M2 is also used for QM-only calculations in order to understand the influence of the protein on the energies and geometries of various stationary points, especially transition states.

Here and in the following, we present tables with relative energies obtained from $\mathrm{QM} / \mathrm{MM}$ geometry optimization $(\mathrm{QM}=$ $\mathrm{B} 3 \mathrm{LYP} / \mathrm{BS} 1$ ) and from $\mathrm{QM} / \mathrm{MM}$ single-point calculations without and with dispersion corrections ( $\mathrm{QM}=\mathrm{B} 3 \mathrm{LYP} /$ TZVPP and QM = B3LYP/TZVPP-D2, respectively). In the text, we normally only quote and discuss the most accurate single-point dispersion-corrected results.

3.2.1. QM Region M1. We first devise a relatively small QM region (M1, 71 atoms, total charge of +1$)$ and consider all three possible spin states $\left(\mathrm{Fe}^{2+}, \mathrm{d}^{6}\right)$, namely singlet, triplet, and quintet. The optimized structures of all stationary points are shown in Figures 3 and 4. The corresponding QM/MM relative energies are listed in Table 2 .

In the reactant complex (React), the substrate $Z$-acetaldoxime binds to the ferrous ion via its nitrogen atom. The singlet state has the shortest $\mathrm{Fe}-\mathrm{N}_{\text {sub }}$ distance $(2.03 \AA)$ and is calculated to be most stable. It is a low-spin hexacoordinated species, consistent with experimental evidence from resonance Raman studies. ${ }^{29,31}$ The $\mathrm{Fe}-\mathrm{N}_{\text {sub }}$ and $\mathrm{Fe}-\mathrm{N}_{\mathrm{His} 299}$ bonds are elongated in the triplet $(2.50 \AA)$ and quintet $(2.47 \AA)$ states, mainly because the antibonding $\sigma_{z}^{2 *}$ orbital is populated by one electron in these states (see natural molecular orbitals in Supporting Information, Figures S4-S6); this phenomenon is well-known from many other theoretical calculations of heme complexes. ${ }^{68-72}$ When the 


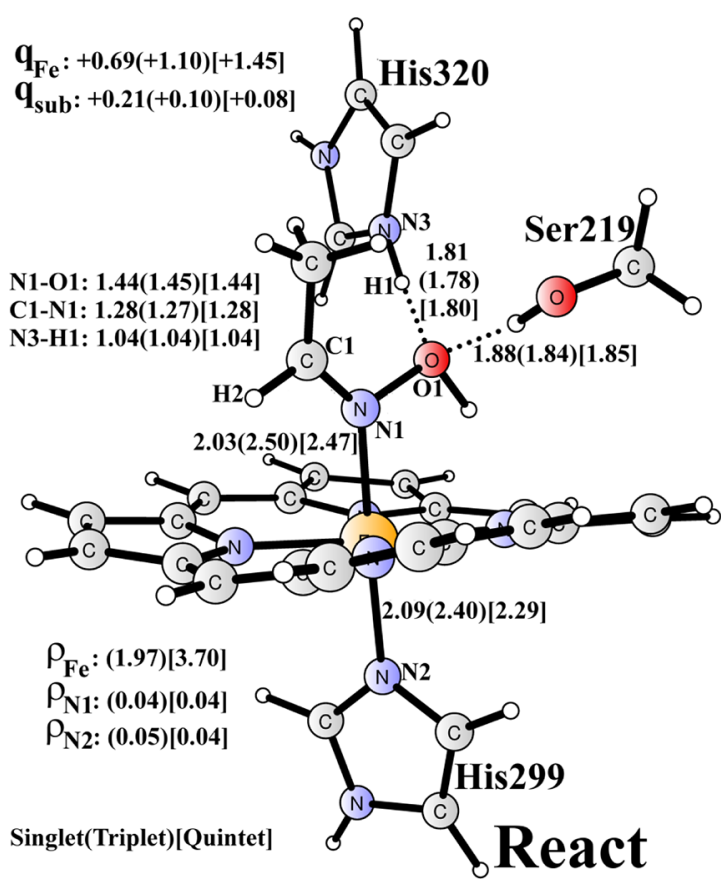

Figure 3. Optimized structure of the reactant complex (React) for QM region M1 (B3LYP/MM). All bond lengths are given in angstroms. NPA charges of $\mathrm{Fe}$ and substrate are given for singlet(triplet)[quintet]. NPA spin densities of selected atoms are shown for (triplet)[quintet].

singlet geometry is used for $\mathrm{QM} / \mathrm{MM}$ single-point calculations on the triplet and quintet, the corresponding energies are both more than $19 \mathrm{kcal} / \mathrm{mol}$ higher than that of the singlet state. At their optimized geometries, the triplet and quintet lie at +3.2 and $+0.8 \mathrm{kcal} / \mathrm{mol}$, respectively, when dispersion is not included, and at +10.9 and $+8.3 \mathrm{kcal} / \mathrm{mol}$, respectively, with dispersion included in a single-point fashion. Clearly, dispersion further favors the singlet state, simply due to the closer contact between the substrate and the heme porphyrin. It should be noted that geometry optimizations with dispersion included affect the relative energies only slightly (by $1-2 \mathrm{kcal} / \mathrm{mol}$ for each spin state of React and Prod, Table 2). Therefore, dispersion effects are always assessed from single-point calculations in the present paper, in line with the common practice in studies of enzymatic reactions. ${ }^{73-77}$ In React, the hydroxy group of acetaldoxime forms two hydrogen bonds to His320 and Ser219, with distances in the range of 1.7-1.9 $\AA$ for all three spin states, which help orient the substrate so that it is ready for the proton transfer coupled $\mathrm{N}-\mathrm{O}$ bond cleavage.

The optimized structures of the $\mathrm{N}-\mathrm{O}$ bond cleavage transition state and the resulting intermediate are shown in Figure 4. The barrier (B3LYP/TZVPP-D2) for N-O cleavage is calculated to be $9.7,18.5$, and $17.5 \mathrm{kcal} / \mathrm{mol}$ for the singlet, triplet, and quintet states, respectively. We note that concomitant with $\mathrm{N}-\mathrm{O}$ bond cleavage, His 320 facilitates the departure of the leaving hydroxide by delivering a proton. The crucial $\mathrm{N}-\mathrm{O}$ distance increases from $1.44 \AA$ in ${ }^{1}$ React to $2.03 \AA$ in ${ }^{1} \mathrm{TS} 1$, while the $\mathrm{Fe}-\mathrm{N} 1$ bond contracts from 2.03 to $1.79 \AA$. The energy of the intermediate Int1 relative to ${ }^{1}$ React is computed to be $-2.9,-0.8$, and 14.7 $\mathrm{kcal} / \mathrm{mol}$ for the broken-symmetry open-shell singlet, the triplet, and the quintet state, respectively. The near-degeneracy of the open-shell singlet and triplet states indicates that both spin states might be populated; the closed-shell singlet with a relative energy of $8.8 \mathrm{kcal} / \mathrm{mol}$ is less stable. Natural orbital analysis gives a large spin density on $\mathrm{N} 1$ for the broken-symmetry open-shell singlet
(0.77), the triplet (0.67), and the quintet state (0.87), suggesting the representation $\mathrm{Fe}^{\mathrm{III}}-\left(\mathrm{CH}_{3} \mathrm{CH}=\mathrm{N}^{\bullet}\right)$ with a singly occupied lone pair orbital at the substrate $\mathrm{N} 1$ atom (see Supporting Information, Figures S10-S12). The electronic structure of ${ }^{3}$ Int1 can thus be interpreted as featuring a low-spin ferric ion $\left(S_{\mathrm{Fe}}=1 / 2\right)$ interacting with the $\mathrm{CH}_{3} \mathrm{CH}=\mathrm{N}^{\bullet}$ radical $(S=1 / 2)$ in a ferromagnetic fashion (as opposed to antiferromagnetic coupling in the broken-symmetry open-shell singlet), while the electronic structure of ${ }^{5}$ Int 1 is best described as an intermediatespin $\mathrm{Fe}(\mathrm{III})$ ion $\left(S_{\mathrm{Fe}}=3 / 2\right)$ ferromagnetically coupled to the $\mathrm{CH}_{3} \mathrm{CH}=\mathrm{N}^{\bullet}$ radical $(S=1 / 2$, see Supporting Information, Figure S12). The closed-shell singlet intermediate might be characterized as $\mathrm{Fe}^{2+}-\left(\mathrm{CH}_{3} \mathrm{CH}=\mathrm{N}^{+}\right)$since the total charge of the $\mathrm{CH}_{3} \mathrm{CH}=\mathrm{N}$ moiety is +0.41 , with iron being less positively charged $(+0.76)$ than in the triplet $(+1.03)$ or quintet $(+1.42)$. At Int 1, the $\mathrm{Fe}-\mathrm{N} 1$ bond length is $1.73 \AA$ for the singlet and $1.88 \AA$ for the triplet.

The subsequent step involves deprotonation of the $\mathrm{CH}_{3} \mathrm{CH}=\mathrm{N}$ moiety, accompanied by electron transfer back to the iron center. His 320 is a suitable base to abstract this proton. ${ }^{41}$ The optimized transition state (TS2) and product (Prod) are shown in Figure 4. The singlet state has the lowest barrier (13.5 $\mathrm{kcal} / \mathrm{mol}$ relative to Int 1 ). The barriers for the triplet and quintet are both around $20 \mathrm{kcal} / \mathrm{mol}$, about $6 \mathrm{kcal} / \mathrm{mol}$ higher than in the singlet. Compared to Int 1 , a rotation around the $\mathrm{Fe}-\mathrm{N} 1$ bond is observed at TS2. At ${ }^{1}$ TS2, the critical $\mathrm{C} 1-\mathrm{H} 2$ and $\mathrm{N} 3-\mathrm{H} 2$ distances are 1.28 and $1.45 \AA$, respectively.

Similarly to React, the acetonitrile product coordinates to the ferrous ion in the singlet state, whereas it dissociates in the triplet and quintet states. The whole reaction is exothermic by as much as $30 \mathrm{kcal} / \mathrm{mol}$, and the three spin states are close to degenerate. Spin crossing from the singlet to higher spin states may facilitate the departure of the acetonitrile product, and another acetaldoxime substrate can bind into the active site to start the next catalytic cycle.

Similarly to our recent comparison of QM-only and QM/MM models for acetylene hydratase, ${ }^{78}$ the $\mathrm{MM}$ point charges of selected residues were set to zero in order to check their electrostatic contributions to the computed relative energies (e.g., barriers). Residues that have a large effect should be included into the QM region so that their interactions with the reaction center are treated at the QM level. In the present case, ${ }^{1}$ React and ${ }^{1}$ TS were selected for this charge deletion analysis (Supporting Information, Table S5). With no charges switched off, the barrier is $15.6 \mathrm{kcal} / \mathrm{mol}$ (QM energy, B3LYP/BS1). Two residues were found to have large effects: Glu143 that is hydrogen-bonded to His320 and Arg178 that is hydrogenbonded to Glu143. The barrier decreases (increases) by 10.2 (6.0) $\mathrm{kcal} / \mathrm{mol}$ upon removal of the MM charges on Glu143 (Arg178). The large effect for $\operatorname{Arg} 178(6.0 \mathrm{kcal} / \mathrm{mol})$ is consistent with the experimental finding that mutations of this residue lead to reduced activity. ${ }^{23}$ All other residues have relatively small effects (less than $3 \mathrm{kcal} / \mathrm{mol}$ ). On the basis of this analysis for M1, we defined a larger QM region (labeled as M2) by adding the side chains of Glu143 and Arg178 as well as three of their hydrogen-bonding partners (two water molecules and the side chain of Ser174) to better capture the influence of these residues on the reaction energetics of the different spin states. The residues Glu143 and Arg178 were also part of the QM region in the recently published $\mathrm{QM} / \mathrm{MM}$ study. ${ }^{41}$

3.2.2. QM Region M2. The large QM region $\mathbf{M} 2$ is composed of $103 \mathrm{QM}$ atoms (Figure 5) and the total charge is +1 (same as in M1). All stationary points for the three different spin states 

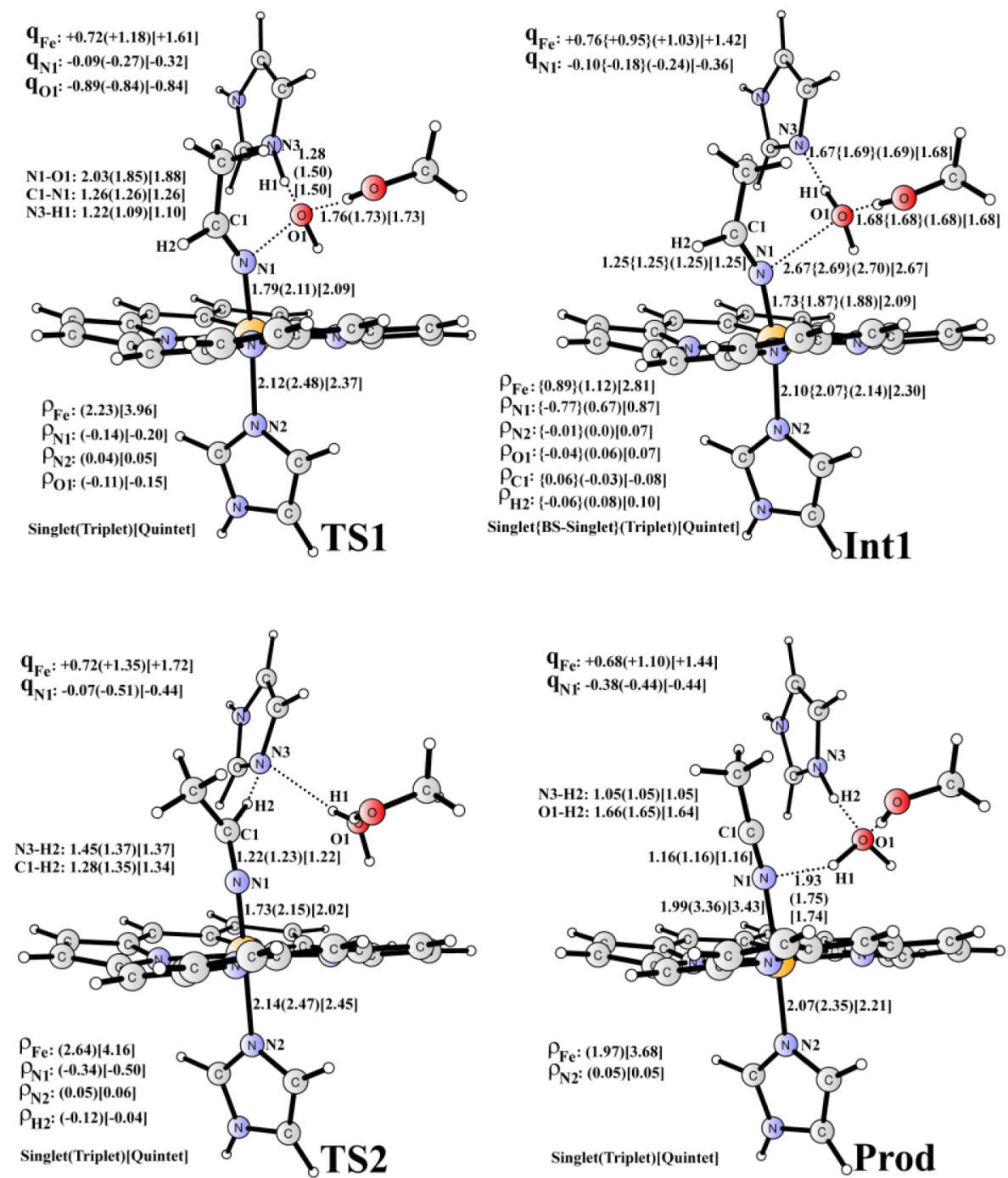

Figure 4. Optimized structure of transition states, intermediate, and product for QM region M1 (B3LYP/MM). All bond lengths are given in Å. NPA charges of selected atoms are given for singlet(triplet)[quintet]. NPA spin densities of selected atoms are shown for (triplet)[quintet] and in the case of Int1 also for the broken-symmetry open-shell singlet.

Table 2. Calculated QM/MM Relative Energies (in kcal/mol) with QM Region M1

\begin{tabular}{lllll}
\multirow{2}{*}{ React } & & B3LYP/BS1 & $\begin{array}{c}\text { B3LYP/ } \\
\text { TZVPP }\end{array}$ & $\begin{array}{c}\text { B3LYP/TZVPP- } \\
\text { D2 }\end{array}$ \\
& singlet & 0 & 0 & 0 \\
& triplet & 5.0 & 3.2 & $10.9\left(9.6^{a}\right)$ \\
& quintet & 1.5 & 0.8 & $8.3\left(6.8^{a}\right)$ \\
\multirow{5}{*}{ In11 } & singlet & 11.4 & 10.8 & 9.7 \\
& triplet & 15.5 & 13.0 & 18.5 \\
& quintet & 13.6 & 12.4 & 17.5 \\
& singlet & $-1.4^{b}\left(11.1^{c}\right)$ & $-4.5^{b}\left(8.1^{c}\right)$ & $-2.9^{b}\left(8.8^{c}\right)$ \\
& triplet & -0.1 & -3.0 & -0.8 \\
& quintet & 6.1 & 8.6 & 14.7 \\
& singlet & 13.7 & 9.3 & 10.6 \\
& triplet & 8.7 & 11.7 & 16.8 \\
& quintet & 14.4 & 10.1 & 16.7 \\
& singlet & -27.4 & -32.4 & $-30.4\left(-30.6^{a}\right)$ \\
& triplet & -33.0 & -40.7 & $-29.7\left(-30.9^{a}\right)$ \\
& quintet & -35.5 & -42.1 & $-30.3\left(-31.4^{a}\right)$
\end{tabular}

${ }^{a}$ B3LYP-D2-optimized geometries. ${ }^{b}$ Broken symmetry open-shell. ${ }^{c}$ Closed-shell. were reoptimized. The resulting structures are shown in the Supporting Information (Figures S19-S21) and the relative energies are listed in Table 3 . The geometries are generally quite similar to those obtained in model M1, with deviations of normally less than $0.1 \AA$ for bond lengths. The largest differences are observed in ${ }^{3} \mathrm{TS} 2$, where the $\mathrm{Fe}-\mathrm{N}$ bonds to the two axial ligands become shorter (by about $0.2-0.3 \AA$ ) compared to M1.

For the reactant complex, we find energy gaps between the spin states for M2 that are very similar to those for M1: the singlet is the ground state, and the triplet and quintet states are both more than $8 \mathrm{kcal} / \mathrm{mol}$ higher. For the first $\mathrm{N}-\mathrm{O}$ bond cleavage step, the calculated barriers for $\mathbf{M} 2$ are about $4-5 \mathrm{kcal} /$ mol higher than those for M1. For example, the energy of ${ }^{1}$ TS1 is $14.2(9.7) \mathrm{kcal} / \mathrm{mol}$ with $\mathbf{M} 2$ (M1). The recently published QM/ MM calculations report a similar barrier for this step $(12.8 \mathrm{kcal} /$ $\mathrm{mol}) .^{41}$ The inclusion of more groups into the QM region (M2 versus M1) does not change the electronic structure of Int1: the open-shell singlet, the triplet, and the quintet states can be described as $\mathrm{Fe}^{\mathrm{III}}-\left(\mathrm{CH}_{3} \mathrm{CH}=\mathrm{N}^{\bullet}\right)$ and the closed-shell singlet as $\mathrm{Fe}^{\mathrm{II}}-\left(\mathrm{CH}_{3} \mathrm{CH}=\mathrm{N}^{+}\right)$.

In more general terms, Int1 is an example of a $\{\mathrm{FeL}\}^{6}$ complex (where 6 is the total number of electrons in the Fe d orbitals and 


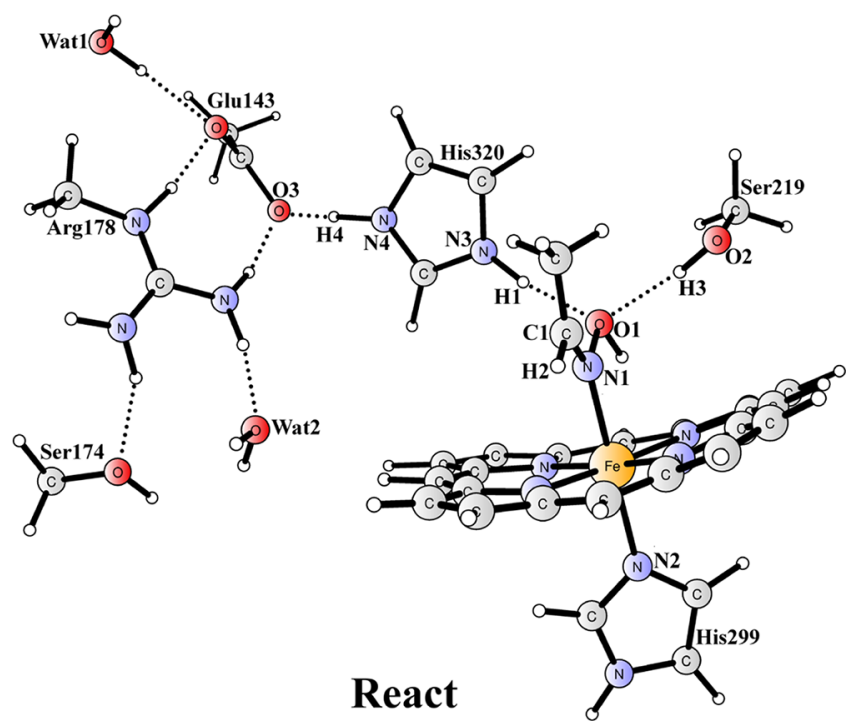

Figure 5. Optimized structure of the reactant complex for QM region M2 (B3LYP/MM). For bond lengths, NPA charges, and NPA spin densities, see Supporting Information (Figure S19).

the $\pi^{*}$ orbitals of the ligand L). It is instructive to compare Int 1 with the well-known $\{\mathrm{FeNO}\}^{6}$ complexes. The latter have a fairly different electronic structure, with a closed-shell singlet ground state, while the quintet is totally repulsive, leading to the release of nitric oxide. ${ }^{38,39,79-81}$ The reason for this difference is that the SOMO of $\mathrm{NO}$ is $1.02 \mathrm{eV}$ higher than that of $\mathrm{CH}_{3} \mathrm{CH}=\mathrm{N}^{\bullet}$ (calculated at the B3LYP/6-31G(d,p) level), which facilitates electron transfer from the SOMO of the $\mathrm{NO}$ radical to one of the $\mathrm{d}$ orbitals $\left(\pi_{x z}{ }^{*}\right.$ or $\left.\pi_{y z}{ }^{*}\right)$ of iron and formation of a closed-shell singlet $\mathrm{Fe}^{\mathrm{II}}\left(\mathrm{NO}^{+}\right)$species. In addition, the LUMO of $\mathrm{CH}_{3} \mathrm{CH}=$ $\mathrm{N}^{\bullet}$ is $2.97 \mathrm{eV}$ higher than that of $\mathrm{NO}$, suggesting much weaker back-donation from the iron to $\mathrm{CH}_{3} \mathrm{CH}=\mathrm{N}^{\bullet}$. The $\mathrm{Fe}-\mathrm{N}-\mathrm{O}$ angles in $\{\mathrm{FeNO}\}^{6}$ complexes are close to linear in most cases, due to two back-donations from $\pi_{x z}{ }^{*}$ and $\pi_{y z}{ }^{*}$ of iron to the two $\pi_{\mathrm{N}=\mathrm{O}} *$ orbitals of $\mathrm{NO}^{82}$ By contrast, the $\mathrm{Fe}-\mathrm{N} 1-\mathrm{C} 1$ angle in Int1 is $151.6^{\circ}\left(155.7^{\circ}\right), 142.3^{\circ}$ and $142.4^{\circ}$ for the open-shell (closed-shell) singlet, the triplet, and the quintet, respectively. The smaller bending angle in the triplet and quintet states will favor the overlap between the $\sigma_{z}{ }^{*}$ orbital of Fe and the singly occupied p orbital at N1 (see Supporting Information, Figure S11), similar as in the case of the ferric heme nitrosyl thiolate complex. ${ }^{83}$ The larger bending angle in the singlet state should facilitate the interaction between the $\pi_{x z}{ }^{*}$ orbital of $\mathrm{Fe}$ and the singly occupied $\mathrm{p}$ orbital at $\mathrm{N} 1$. The $\mathrm{Fe}-\mathrm{N} 1$ bond length is $1.87(1.73), 1.88$, and $2.09 \AA$ for the open-shell (closed-shell) singlet, triplet, and quintet, respectively. The singlet and triplet distances are quite similar to those in iron-nitrene complexes, ${ }^{84-89}$ suggesting at least partial multiple bond character.

The computed barriers for the second reaction step are also higher for $\mathbf{M} 2$ than for M1. It should be noted that the triplet barrier $(15.2 \mathrm{kcal} / \mathrm{mol})$ is now slightly lower than the singlet barrier $(15.5 \mathrm{kcal} / \mathrm{mol})$, but the difference is so small that the reaction may proceed through both spin states, indicating twostate reactivity ${ }^{42,43}$ for Oxd. The quintet barrier is too high (30.5 $\mathrm{kcal} / \mathrm{mol}$ ) to be a viable choice. During the proton transfer, one electron transfers to the metal center, thus the redox state of iron goes back to +2 in this step.

As seen from Table 3, the calculated QM/MM energy difference between the two lowest-energy transition states $\left({ }^{1} \mathrm{TS} 1\right.$ and ${ }^{3}$ TS2 $)$ is too small $(1.0 \mathrm{kcal} / \mathrm{mol})$ to assign the rate-limiting step unambiguously. Experimental rate constants for various $Z$ and $E$-aldoximes have been reported ${ }^{19,23,30,31,33}$ in the range of $1.5 \times 10^{-3}$ to $3.2 \times 10^{3} \mathrm{~s}^{-1}$, which can be converted to barriers in the range of $13-21 \mathrm{kcal} / \mathrm{mol}$ using classical transition state theory. The calculated barriers with QM region M2 ( 14-15 $\mathrm{kcal} / \mathrm{mol})$ are in reasonable agreement with the experimental kinetic results. In the enzyme, the barrier is thus lowered by more than $20 \mathrm{kcal} / \mathrm{mol}$ compared with the uncatalyzed reaction in solution, suggesting a rate enhancement of the order of $10^{15}$. Calculations with the small QM region M1 underestimate the barriers by several $\mathrm{kcal} / \mathrm{mol}$, mainly due to the less accurate description of the electrostatic interactions between His320 and its neighboring residues, Glu143 and Arg178.

The ferrous heme catalyzes the $\mathrm{N}-\mathrm{O}$ bond cleavage by acting as an electron donor, transferring one electron from the $\pi_{x z}{ }^{*}$ to the $\sigma_{\mathrm{N}-\mathrm{O}} *$ orbital (see Supporting Information, Figures S4S12). In nitrite reductase, the ferrous heme plays a similar role. ${ }^{90-92}$ Single-bond cleavage reactions promoted by heme iron oxidation are also found in the formation of Compound I

Table 3. Calculated QM/MM and QM-Only Relative Energies (in kcal/mol) with QM Region M2

\begin{tabular}{|c|c|c|c|c|c|}
\hline & & \multicolumn{3}{|c|}{$\mathrm{QM} / \mathrm{MM}$} & \multirow[b]{2}{*}{ QM-only } \\
\hline & & B3LYP/BS1 & B3LYP/TZVPP & B3LYP/TZVPP-D2 & \\
\hline \multirow[t]{3}{*}{ React } & singlet & 0 & 0 & 0 & 0 \\
\hline & triplet & 4.9 & 3.3 & 10.7 & 6.9 \\
\hline & quintet & 1.7 & 1.2 & 8.4 & 5.5 \\
\hline \multirow[t]{3}{*}{ TS1 } & singlet & 16.8 & 15.7 & 14.2 & 21.0 \\
\hline & triplet & 19.7 & 16.9 & 22.3 & 30.7 \\
\hline & quintet & 17.9 & 16.3 & 21.3 & 28.0 \\
\hline \multirow[t]{3}{*}{ Int 1} & singlet & $2.2^{a}\left(11.1^{b}\right)$ & $-1.7^{a}\left(7.7^{b}\right)$ & $-0.6^{a}\left(7.4^{b}\right)$ & $4.6^{a}\left(12.0^{b}\right)$ \\
\hline & triplet & 3.6 & 0.3 & 1.9 & 9.1 \\
\hline & quintet & 6.2 & 7.6 & 13.1 & 16.6 \\
\hline \multirow[t]{3}{*}{ TS2 } & singlet & 18.8 & 14.0 & 14.9 & 14.1 \\
\hline & triplet & 18.0 & 14.4 & 14.6 & 20.0 \\
\hline & quintet & 19.3 & 23.9 & 29.9 & 26.9 \\
\hline \multirow[t]{3}{*}{ Prod } & singlet & -24.5 & -29.5 & -27.5 & -32.6 \\
\hline & triplet & -30.2 & -36.6 & -25.6 & -35.0 \\
\hline & quintet & -31.9 & -38.5 & -26.8 & -35.5 \\
\hline
\end{tabular}

${ }^{a}$ Broken-symmetry open-shell singlet. ${ }^{b}$ Closed-shell singlet. 
$(\mathrm{CpdI})^{93-104}$ as well as other types of $\mathrm{O}-\mathrm{O}$ bond-breaking reactions. ${ }^{105-107}$ In order to analyze the relative propensities of $\mathrm{Fe}^{2+}$ and $\mathrm{Fe}^{3+}$ acting as electron donor in aldoxime dehydratase, the structures of React and Int1 were used as starting geometries for reoptimizations, with the ferrous ion replaced by a ferric ion. The optimized structures and relative energies for the doublet, quartet, and sextet states are shown in Supporting Information (Figure S22 and Table S7). In the reactant complex, the doublet has the lowest energy, followed by quartet and sextet (higher by 1.2 and $6.2 \mathrm{kcal} / \mathrm{mol}$, respectively). Dispersion makes an important contribution to the relative energies of these spin states-when it is not included, the quartet becomes the ground state $(4.8 \mathrm{kcal} / \mathrm{mol}$ below the doublet $)$. We were able to locate the intermediates Int1 for all three spin states, but they all lie about $40 \mathrm{kcal} / \mathrm{mol}$ higher than React. This is as expected from the much higher redox potential for $\mathrm{Fe}^{4+} / \mathrm{Fe}^{3+}$ (or $\mathrm{Fe}^{3+}$ porphyrin radical cation $/ \mathrm{Fe}^{3+}$ ) compared with $\mathrm{Fe}^{3+} / \mathrm{Fe}^{2+}$. For example, a reduction potential difference of about $0.8 \mathrm{~V}$ was measured for myoglobin, ${ }^{108,109}$ in which the heme is also bound to a histidine residue in the active site. According to the computed spin densities, the electronic structure of Int1 corresponds to a $\mathrm{Fe}^{\mathrm{III}}$-porphyrin radical cation interacting with $\mathrm{CH}_{3} \mathrm{CH}=\mathrm{N}^{\bullet} .{ }^{2}$ Int1 is best described as a low-spin $\mathrm{Fe}^{\mathrm{III}}\left(S_{\mathrm{Fe}}=\right.$ $1 / 2$ ) ferromagnetically coupled to the porphyrin radical cation $\left(S_{\text {por }}=1 / 2\right)$ and antiferromagnetically coupled to $\mathrm{CH}_{3} \mathrm{CH}=\mathrm{N}^{\bullet}$ radical $(S=1 / 2)$. In ${ }^{4}$ Int1, the low-spin ferric ion is ferromagnetically coupled to both radicals. ${ }^{6}$ Int1 has an intermediate-spin ferric center $\left(S_{\mathrm{Fe}}=3 / 2\right)$ that is ferromagnetically interacting with both radicals. During $\mathrm{N}-\mathrm{O}$ bond cleavage, one electron is transferred from the porphyrin to the acetaldoxime, rather than from the iron center, and thus the ferric ion actually keeps its oxidation state during this process. In summary, if the substrate binds to the ferric ion via its nitrogen atom, the formation of Int1 via $\mathrm{N}-\mathrm{O}$ bond cleavage is highly endothermic so that aldoximes cannot be transformed into nitriles in this manner.

3.2.3. QM-Only Calculations. To check the influence of the $\mathrm{MM}$ region on the geometric parameters of various stationary points and their corresponding energies, we performed QM-only calculations with a cluster model extracted from the final structure of the MD simulations. The size of this model is exactly the same as QM region M2 as shown above (103 atoms, total charge of +1$)$. In line with the standard QM-only approach, ${ }^{60-62}$ certain atoms at the periphery of the model were kept fixed during the geometry optimizations, and they are marked with asterisks in the figures (Supporting Information, Figures S23S25).

As shown in Table 3, the relative energies of the two transition states and of the intermediate are raised by several $\mathrm{kcal} / \mathrm{mol}$ compared to the $\mathrm{QM} / \mathrm{MM}$ results, with the largest deviation being about $8 \mathrm{kcal} / \mathrm{mol}$. This increase in the barriers can also be understood from the residue interaction analysis (Supporting Information, Table S5), which shows that many charged residues within $15 \AA$ of the iron are capable of lowering the barrier by $1-3$ $\mathrm{kcal} / \mathrm{mol}$. The summed electrostatic effects cannot be disregarded, and the use of continuum solvation is apparently not sufficient to capture the environmental effects for the chosen QM-only model (103 atoms); a much larger QM region would seem to be required for covering these effects (possibly 200-300 atoms). However, there are trends that are well reproduced by the current QM-only model. In the reactant complex, the singlet is the ground state, and the triplet and quintet are higher and have similar energies. The $\mathrm{N}-\mathrm{O}$ bond cleavage proceeds via the singlet state. The electronic structure of Int1 is qualitatively the same for both QM-only and QM/MM models: the closed-shell singlet state is described as $\mathrm{Fe}^{\mathrm{II}}\left(\mathrm{CH}_{3} \mathrm{CH}=\mathrm{N}^{+}\right)$, and the openshell singlet, the triplet, and the quintet states as $\mathrm{Fe}^{\mathrm{III}}\left(\mathrm{CH}_{3} \mathrm{CH}=\right.$ $\mathrm{N}^{\bullet}$ ). The QM-only and QM/MM spin densities on iron and other atoms are quite similar for Int1 as well as other stationary points. The first step is rate-limiting in the QM-only calculations, with a barrier of $21 \mathrm{kcal} / \mathrm{mol}$, which is about $5 \mathrm{kcal} / \mathrm{mol}$ higher than that from $\mathrm{QM} / \mathrm{MM}$ calculations. Finally, the overall exothermicity of the reaction is more than $30 \mathrm{kcal} / \mathrm{mol}$ at the QM-only level, and thus almost $10 \mathrm{kcal} / \mathrm{mol}$ larger than the QM/ MM value.

Another important issue is whether the QM-only and QM/ MM models give similar structures for the relevant stationary points, especially transition states. In Table 4, key geometric

Table 4. Key Distances (in Å) in TS1 and TS2 from QM/MM and QM-Only Geometry Optimizations $(\mathrm{QM}=\mathrm{B} 3 \mathrm{LYP} / \mathrm{BS1})$

\begin{tabular}{|c|c|c|c|c|c|c|c|}
\hline & \multicolumn{3}{|c|}{$\mathrm{QM} / \mathrm{MM}$} & \multicolumn{3}{|c|}{ QM-only } \\
\hline & & singlet & triplet & quintet & singlet & triplet & quintet \\
\hline \multirow[t]{4}{*}{ TS1 } & $\mathrm{Fe}-\mathrm{N} 1$ & 1.78 & 2.09 & 2.07 & 1.77 & 2.08 & 2.18 \\
\hline & $\mathrm{N} 1-\mathrm{O} 1$ & 2.08 & 1.87 & 1.91 & 2.10 & 1.87 & 2.06 \\
\hline & $\mathrm{O} 1-\mathrm{H} 1$ & 1.29 & 1.55 & 1.54 & 1.19 & 1.50 & 1.30 \\
\hline & N3-H1 & 1.22 & 1.08 & 1.08 & 1.31 & 1.08 & 1.18 \\
\hline \multirow[t]{4}{*}{ TS2 } & $\mathrm{Fe}-\mathrm{N} 1$ & 1.73 & 1.96 & 2.02 & 1.73 & 1.96 & 2.03 \\
\hline & $\mathrm{C} 1-\mathrm{N} 1$ & 1.22 & 1.23 & 1.22 & 1.22 & 1.23 & 1.22 \\
\hline & $\mathrm{C} 1-\mathrm{H} 2$ & 1.26 & 1.31 & 1.34 & 1.31 & 1.45 & 1.32 \\
\hline & $\mathrm{N} 3-\mathrm{H} 2$ & 1.49 & 1.42 & 1.37 & 1.48 & 1.32 & 1.42 \\
\hline
\end{tabular}

parameters are summarized for the two transition states in all three spin states. It can be seen that the MM environment has significant effects on the proton-transfer reaction coordinate, while the distances between heavy atoms are less affected. The deviations between the QM-only and QM/MM results appear to be smallest for the singlet, and larger for the triplet and quintet states (up to $0.1-0.2 \AA$ ). They are expected to decrease when using larger QM regions (currently 103 atoms).

3.3. $\mathrm{Fe}^{2+}$-Catalyzed E-Acetaldoxime Dehydration. Both $Z$ - and $E$-aldoximes can be dehydrated by Oxd enzymes, but in some cases, the $Z$-form is preferred. ${ }^{3}$ One possible reason could be the steric repulsion between the $\alpha$-substituent and the porphyrin ring during formation of the reactant complex. QM/ MM calculations on the dehydration of $E$-acetaldoxime with QM region $\mathbf{M} 2$ were performed to check this notion. The optimized reactant complex, transition state, and intermediate are shown in Supporting Information (Figures S26 and S27), and the QM/ MM relative energies at various levels are listed in Table 5.

Similarly to $Z$-acetaldoxime, the reaction complex (React) of $E$-acetaldoxime has a singlet ground state. Its energy is $6.2 \mathrm{kcal} /$ mol higher than that for $Z$-acetaldoxime. If dispersion is not included, the quintet becomes the ground state. The steric repulsion between the $\alpha$-methyl group of the substrate and the porphyrin ring hinders substrate coordination, as can be seen from the large $\mathrm{Fe}-\mathrm{N} 1$ distances in all spin states. For example, the $\mathrm{Fe}-\mathrm{N} 1$ bond in ${ }^{1}$ React is $0.12 \AA$ ( $2.15 \AA$ versus $2.03 \AA$ ) longer for $E$ - than for $Z$-acetaldoxime. In addition, the $\mathrm{Fe}-\mathrm{N} 1-$ $\mathrm{C} 1$ angle is also larger in the $E$ - than the $Z$-form $\left(141.7^{\circ}\right.$ versus $133.2^{\circ}$ ). Larger $\alpha$-substituents may further impede the binding of $E$-aldoximes and thus reduce the reactivity toward dehydration.

Relative to the corresponding reactant complex, the computed barriers for $\mathrm{N}-\mathrm{O}$ bond cleavage are quite similar for $\mathrm{E}$ - and $\mathrm{Z}$ acetaldoxime ( 13.7 versus $14.2 \mathrm{kcal} / \mathrm{mol}$ in the favored singlet 
Table 5. Calculated QM/MM Energies (in kcal/mol) for E-Acetaldoxime Dehydration with QM Region M2 (Relative to the Singlet Ground State of React of Z-Acetaldoxime)

\begin{tabular}{|c|c|c|c|c|c|}
\hline & & \multicolumn{3}{|c|}{$E$-acetaldoxime } & \multirow{2}{*}{$\frac{Z \text {-acetaldoxime }}{\text { B3LYP/TZVPP-D2 }}$} \\
\hline & & B3LYP/BS1 & B3LYP/TZVPP & B3LYP/TZVPP-D2 & \\
\hline \multirow[t]{3}{*}{ React } & singlet & 7.4 & 7.6 & 6.2 & 0 \\
\hline & triplet & 6.7 & 5.1 & 12.7 & 10.7 \\
\hline & quintet & 3.3 & 2.5 & 9.3 & 8.4 \\
\hline \multirow[t]{3}{*}{ TS1 } & singlet & 24.3 & 22.5 & 19.9 & 14.2 \\
\hline & triplet & 27.5 & 25.6 & 27.4 & 22.3 \\
\hline & quintet & 24.0 & 22.3 & 26.0 & 21.3 \\
\hline \multirow[t]{3}{*}{ Int1 } & singlet & $4.5^{a}\left(13.2^{b}\right)$ & $-0.5^{a}\left(8.3^{b}\right)$ & $1.5^{a}\left(9.4^{b}\right)$ & $-0.6^{a}\left(7.4^{b}\right)$ \\
\hline & triplet & 7.1 & 2.9 & 4.5 & 1.9 \\
\hline & quintet & 6.5 & 1.4 & 7.6 & 13.1 \\
\hline
\end{tabular}

${ }^{a}$ Broken-symmetry open-shell singlet. ${ }^{b}$ Closed-shell singlet.
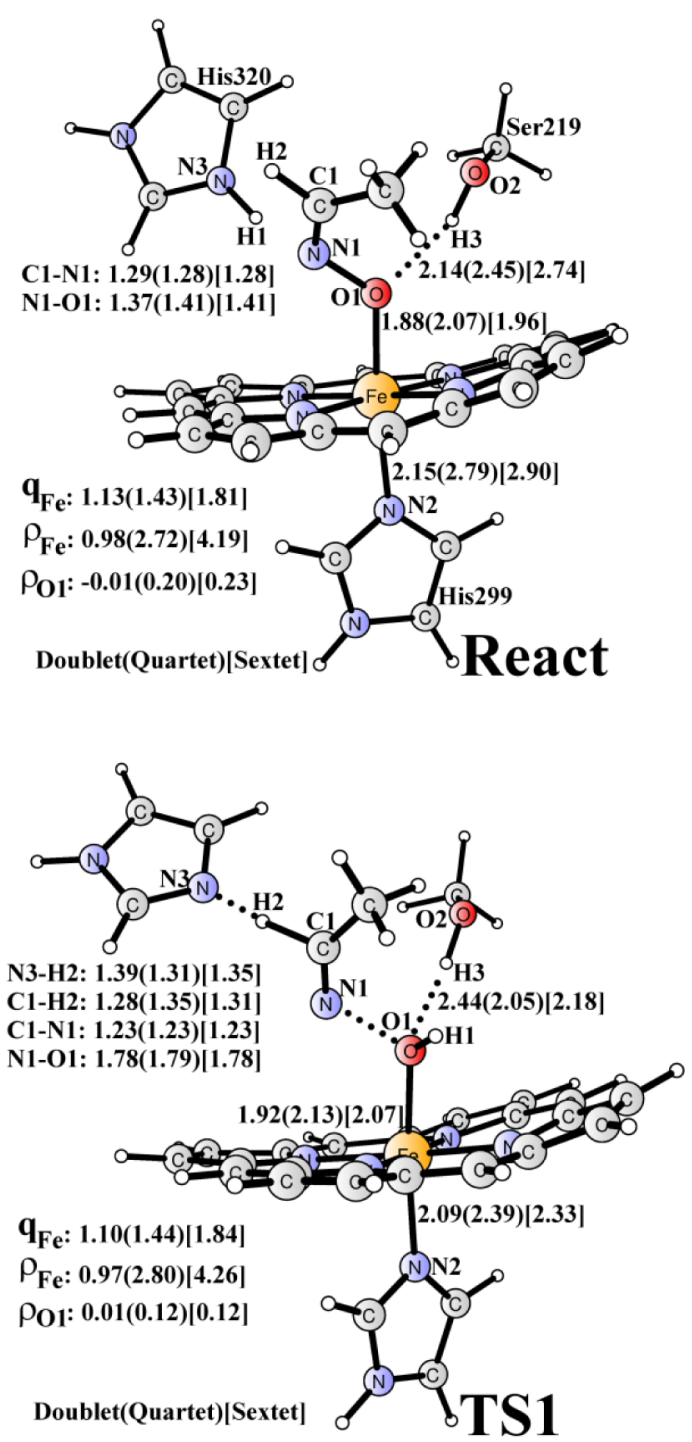
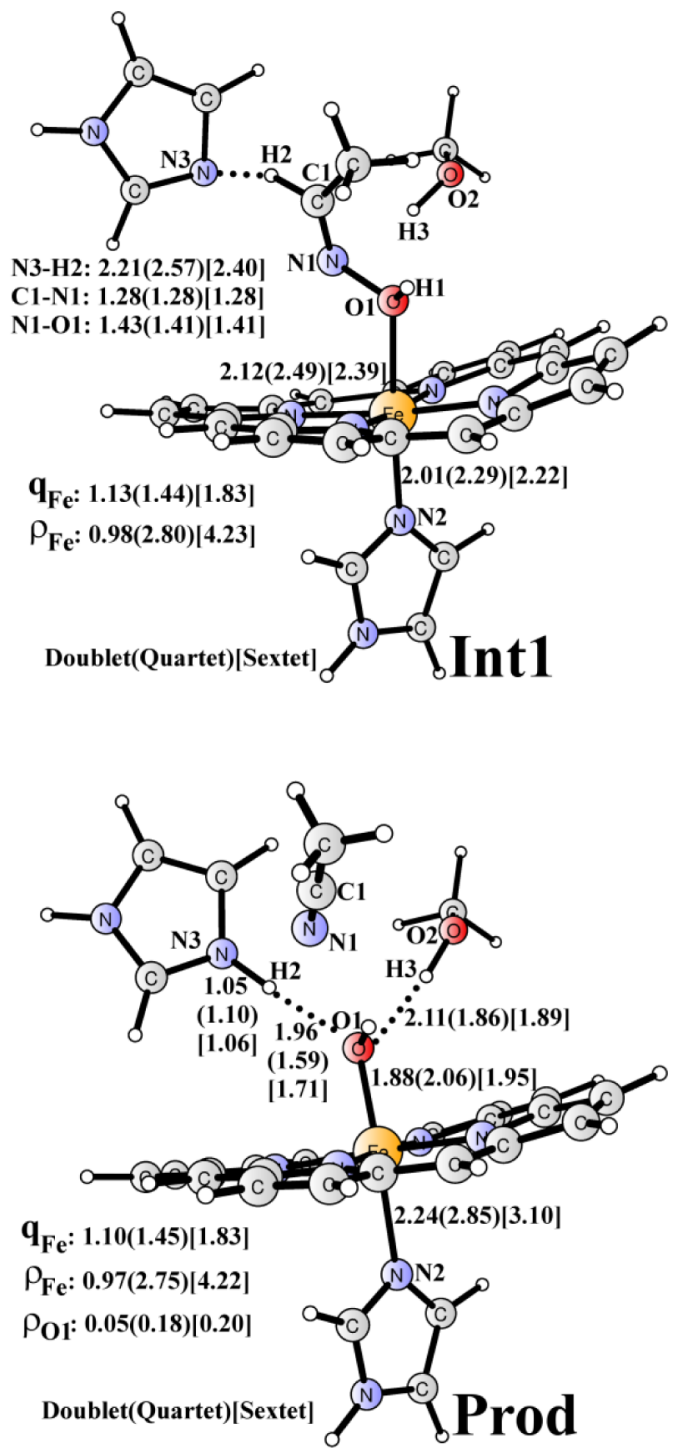

Figure 6. Optimized structures of reactant, intermediate, transition state, and product for the $\mathrm{Fe}^{3+}$-catalyzed $\mathrm{Z}$-acetaldoxime dehydration for $\mathrm{QM}$ region M1 (B3LYP/MM). All bond lengths are given in angstroms. NPA charges of iron are given for the singlet(triplet)[quintet]. NPA spin densities of iron are shown for the (triplet)[quintet].

state). Likewise, the key geometric parameters of the transition state TS1 are fairly similar with both substrates; for example, the length of the scissile N1-O1 bond is $2.12 \AA$ for E-acetaldoxime and $2.08 \AA$ for $Z$-acetaldoxime. In the intermediate Int1, the open-shell singlet, the triplet, and the quintet state again have the same electronic character, $\mathrm{Fe}^{\mathrm{III}}\left(\mathrm{CH}_{3} \mathrm{CH}=\mathrm{N}^{\bullet}\right)$. The bending angle of $\mathrm{Fe}-\mathrm{N} 1-\mathrm{C} 1$ in the triplet state of Int1 is larger for $E$ than for $Z$-acetaldoxime $\left(161.2^{\circ}\right.$ versus $\left.142.3^{\circ}\right)$. The following 
deprotonation proceeds via a transition state TS2 that is again qualitatively the same for both substrates in each spin state; the lowest barrier for $E$-acetaldoxime is found in the triplet manifold (13.1 $\mathrm{kcal} / \mathrm{mol}$ relative to open-shell ${ }^{1}$ Int1). The QM/MM results thus indicate two-state reactivity for $E$-acetaldoxime dehydration, with the first step in the singlet state (barrier of 13.7 $\mathrm{kcal} / \mathrm{mol}$ ) followed by a triplet reaction (barrier of $13.1 \mathrm{kcal} /$ $\mathrm{mol})$.

In summary, according to the QM/MM calculations, sterically unencumbered $E$-aldoximes can be dehydrated in the enzyme with similar rate as the corresponding $Z$-aldoximes. Sterically demanding $E$-aldoximes with large $\alpha$-substituents may experience significant steric repulsion with the porphyrin ring, which could prohibit binding and thus prevent the reaction.

3.4. $\mathrm{Fe}^{3+}$-Catalyzed Z-Acetaldoxime Dehydration. In section 3.2.2, we have shown that if the substrate binds to the ferric ion via its nitrogen atom in the same manner as in the ferrous case, $\mathrm{N}-\mathrm{O}$ bond cleavage cannot occur via redox catalysis. However, as mentioned in the Introduction, the substrate aldoxime may alternatively prefer to coordinate to the ferric ion via its oxygen atom, which may be converted into an oxyanion by releasing a proton to solution. ${ }^{25}$ Here we consider this possibility and report QM/MM results obtained with two QM regions (M1 and M2) consisting of 70 and 102 atoms, respectively, with a total charge of +1 . Contrary to the previously considered ferrous case, the $Z$-acetaldoxime is now deprotonated and coordinates to the ferric ion via its oxyanion.

3.4.1. QM Region M1. Given that oxidizing the ferric heme is not a viable option for the dehydration of aldoximes, the ferric ion could alternatively function as a Lewis acid that stabilizes the leaving hydroxide, and a base would then be required to abstract the $\alpha$-proton. This mechanistic scenario is reminiscent of the second-shell mechanism of nitrile hydratase, in which a $\mathrm{Fe}^{3+}$ bound hydroxide performs a nucleophilic attack on the nitrile carbon and a cysteine sulfenic acid delivers a proton to the nitrogen. $^{110}$

The reactant complex (React, Figure 6) has a doublet ground state, with the quartet and sextet being 8.0 and $10.1 \mathrm{kcal} / \mathrm{mol}$ higher, respectively (Table 6 ). The substrate $Z$-acetaldoxime is anionic and bound to $\mathrm{Fe}^{\mathrm{III}}$ via its oxygen atom, while His320 is protonated. A neutral His 320 residue could be a suitable base to abstract a proton, in analogy to the intermediate of the ferrouscatalyzed reaction. We thus consider a proton transfer from

Table 6. Calculated QM/MM Relative Energies (in kcal/mol) for the $\mathrm{Fe}^{3+}$-Catalyzed Reaction with QM Regions M1 and M2

\begin{tabular}{|c|c|c|c|c|c|}
\hline & & \multicolumn{2}{|c|}{ M1 } & \multicolumn{2}{|c|}{ M2 } \\
\hline & & $\begin{array}{l}\text { B3LYP/ } \\
\text { TZVPP }\end{array}$ & $\begin{array}{c}\text { B3LYP/ } \\
\text { TZVPP-D2 }\end{array}$ & $\begin{array}{l}\text { B3LYP/ } \\
\text { TZVPP }\end{array}$ & $\begin{array}{c}\text { B3LYP/ } \\
\text { TZVPP-D2 }\end{array}$ \\
\hline \multirow[t]{3}{*}{ React } & doublet & 0 & 0 & 0 & 0 \\
\hline & quartet & 4.2 & 8.0 & 4.4 & 9.0 \\
\hline & sextet & 5.2 & 10.1 & 5.3 & 11.2 \\
\hline \multirow[t]{3}{*}{ Int 1} & doublet & 20.0 & 22.1 & 22.7 & 24.8 \\
\hline & quartet & 9.1 & 15.9 & 12.2 & 19.3 \\
\hline & sextet & 15.1 & 21.7 & 18.2 & 25.1 \\
\hline \multirow[t]{3}{*}{ TS1 } & doublet & 26.4 & 29.2 & 28.5 & 30.3 \\
\hline & quartet & 24.1 & 30.4 & 25.8 & 31.1 \\
\hline & sextet & 26.5 & 32.8 & 28.3 & 33.8 \\
\hline \multirow[t]{3}{*}{ Prod } & doublet & -36.7 & -32.0 & -36.6 & -30.8 \\
\hline & quartet & -41.6 & -32.3 & -40.8 & -31.0 \\
\hline & sextet & -42.0 & -30.7 & -41.4 & -29.4 \\
\hline
\end{tabular}

His320 to the anionic aldoxime to generate a corresponding intermediate Int1. This proton relocation is endothermic by 15.9 $\mathrm{kcal} / \mathrm{mol}$ and results in a spin crossing to the quartet state. In Int1, the ferric ion and His320 act as Lewis acid and base, respectively, to promote the dehydration. We were able to locate the concerted transition states for dehydration in all three spin states and to confirm that they are directly connected with the nitrile product complexes; there are no cationic or anionic intermediates. The lowest barrier is found for the doublet state. It is calculated to be $13.3 \mathrm{kcal} / \mathrm{mol}$ relative to ${ }^{4}$ Int 1, which might sound reasonable. However, since ${ }^{4}$ Int1 lies $15.9 \mathrm{kcal} / \mathrm{mol}$ above ${ }^{2}$ React, the total barrier becomes $29.2 \mathrm{kcal} / \mathrm{mol}$, which is about $14 \mathrm{kcal} / \mathrm{mol}$ higher than that for the ferrous ion catalyzed reaction.

3.4.2. QM Region M2. The larger QM region $\mathbf{M} 2$ has been used to investigate the influence of the QM region on the reaction energetics of $\mathrm{Fe}^{3+}$-catalyzed dehydration (Table 6; for optimized structures, see Supporting Information, Figures S28 and S29). In analogy to the $\mathrm{Fe}^{2+}$ case, the use of M2 increases the energy of the intermediate and the barrier compared with M1. The most stable quartet intermediate ${ }^{4}$ Int1 lies at $+19.3(+12.2)$ $\mathrm{kcal} / \mathrm{mol}$, and the total overall barrier is $30.3(28.5) \mathrm{kcal} / \mathrm{mol}$ with M2 (M1). Both models predict the same type of two-state reactivity, with the most stable spin states during dehydration evolving from ${ }^{2}$ React via ${ }^{4}$ Int1 and ${ }^{2}$ TS1 to ${ }^{4}$ Prod.

The high computed barriers are consistent with the experimental observation that the ferric form of Oxd enzymes is not active. In the Lewis acid-base scenario considered here, the main problem is that the required formation of the Lewis base (neutral His320) is highly endothermic in the enzyme.

\section{CONCLUSION}

In the present paper, we have addressed the catalytic mechanism and the " $\mathrm{Fe}^{2+}$ vs $\mathrm{Fe}^{3+}$ " ion selectivity of aldoxime dehydratase. Reaction pathways for the uncatalyzed reaction and the enzymatic reaction have been determined both for the ferrous and the ferric form of the heme in all three possible spin states. The oxidation state of iron is confirmed to be crucial for the enzyme activity. The calculations yield feasible barriers for the ferrous form and confirm that it is active, while the ferric form of the enzyme is found to be inactive.

The uncatalyzed reactions for both $Z$ - and E-acetaldoxime were studied with the assistance of three and four water molecules, and both were found to have high barriers of around $36 \mathrm{kcal} / \mathrm{mol}$. In these microsolvated systems, $\mathrm{N}-\mathrm{O}$ bond cleavage and dehydration take place in one concerted step.

In the enzyme, binding of $Z$-acetaldoxime leads to the formation of a six-coordinated singlet ferrous species, in accordance with resonance Raman results. The ferrous heme catalyzes the $\mathrm{N}-\mathrm{O}$ bond cleavage by a one-electron transfer from an iron $\mathrm{d}$ orbital to an antibonding $\sigma_{\mathrm{N}-\mathrm{O}}{ }^{*}$ orbital, while the protonated His320 residue delivers a proton to the leaving hydroxide, generating a water molecule. The key intermediate is characterized as $\mathrm{Fe}^{\mathrm{III}}\left(\mathrm{CH}_{3} \mathrm{CH}=\mathrm{N}^{\bullet}\right)$, which can be present as triplet or open-shell singlet. In the following step, the newly formed neutral His 320 residue abstracts a proton from the intermediate, coupled with electron transfer back to the iron center, thereby forming the nitrile product. Both steps are calculated to have viable barriers, around $14-15 \mathrm{kcal} / \mathrm{mol}$, in reasonable agreement with experimental kinetic studies. The whole reaction is exothermic by about $30 \mathrm{kcal} / \mathrm{mol}$, and spin transition from singlet to quintet could facilitate the dissociation of the nitrile product. This two-step mechanism is fully 
consistent with the results of a recent QM/MM study on the dehydration of $Z$-propionaldehyde, which only covered catalysis by the ferrous heme form of the enzyme in the singlet manifold. ${ }^{41}$

The present QM-only calculations with exactly the same QM region as in our QM/MM work (M2, 103 atoms) give a qualitatively similar picture for the reaction mechanism. However, the calculated barriers are about $7 \mathrm{kcal} / \mathrm{mol}$ higher, and key distances in the optimized transition states vary by up to $0.2 \AA$ in the QM-only and QM/MM models.

The E-acetaldoxime isomer coordinates to the ferrous center less strongly, mainly due to the steric repulsion between its $\alpha$ methyl group and the porphyrin ring. The reactivities of $E$ - and $Z$-acetaldoxime are found to be similar. Both share the same type of transition states for each step, with a close correspondence in the computed geometries and barriers especially for the initial $\mathrm{N}-\mathrm{O}$ bond cleavage. Experimentally, certain $E$-aldoximes cannot be dehydrated by Oxd enzymes. Given the good intrinsic reactivity of E-acetaldoxime, this is probably due to steric congestion for substrates with large $\alpha$-substituents, which will impede substrate binding.

When the heme iron is in the ferric form, the dehydration is associated with high barriers. If the substrate binds to the ferric ion via its nitrogen atom, exactly as in the case of the ferrous ion, the reductive $\mathrm{N}-\mathrm{O}$ bond cleavage is promoted by electron transfer from the porphyrin and is highly endothermic, by more than $40 \mathrm{kcal} / \mathrm{mol}$. In the alternative binding mode, in which the aldoxime coordinates to the ferric ion through its oxygen atom as an oxyanion (after release of a proton), the dehydration can be accomplished through Lewis acid-base catalysis involving the ferric ion and the neutral His 320 residue. The formation of the latter is highly endothermic, however, so that the overall barrier amounts to almost $30 \mathrm{kcal} / \mathrm{mol}$. These findings rationalize the experimental observation that the ferric Oxd enzyme is not active.

\section{ASSOCIATED CONTENT}

\section{S Supporting Information}

Setup of the systems; CHARMM parameters; IRC profiles and coordinates for uncatalyzed reaction; active regions for $\mathrm{QM} / \mathrm{MM}$ optimizations; QM, MM, and QM/MM energies for all stationary points; electrostatic interaction energies from charge deletion analysis; selected molecular orbitals for M1; optimized structures for M2 $\left(\mathrm{Fe}^{2+}\right.$ and $\left.\mathrm{Fe}^{3+}\right)$. Full citations for refs 47, 49, and 59. This material is available free of charge via the Internet at http://pubs.acs.org.

\section{AUTHOR INFORMATION}

\section{Corresponding Author}

*E-mail: thiel@kofo.mpg.de.

\section{Notes}

The authors declare no competing financial interest.

\section{ACKNOWLEDGMENTS}

This work was supported by the Max Planck Society and the Volkswagenstiftung.

\section{REFERENCES}

(1) Asano, Y.; Kato, Y. FEMS Microbiol. Lett. 1998, 158, 185-190.

(2) Kato, Y.; Ooi, R.; Asano, Y. J. Mol. Catal. B: Enzym. 1999, 6, 249256.

(3) Kato, Y.; Nakamura, K.; Sakiyama, H.; Mayhew, S. G.; Asano, Y. Biochemistry 2000, 39, 800-809.
(4) Kato, Y.; Ooi, R.; Asano, Y. Appl. Environ. Microbiol. 2000, 66, 2290-2296.

(5) Choi, E.; Lee, C.; Na, Y.; Chang, S. Org. Lett. 2002, 4, 2369-2371.

(6) Thomas, B.; Prathapan, S.; Sugunan, S. Microporous Mesoporous Mater. 2005, 79, 21-27.

(7) Yamaguchi, K.; Fujiwara, H.; Ogsawara, Y.; Kotani, M.; Mizuno, N. Angew. Chem., Int. Ed. 2007, 46, 3922-3925.

(8) Yang, S. H.; Chang, S. Org. Lett. 2001, 3, 4209-4211.

(9) Ishihara, K.; Furuya, Y.; Yamamoto, H. Angew. Chem., Int. Ed. 2002, 41, 2983-2986.

(10) Narsaiah, A. V.; Nagaiah, K. Adv. Synth. Catal. 2004, 346, 12711274.

(11) Singh, M. K.; Lakshman, M. K. J. Org. Chem. 2009, 74, 30793084.

(12) Dawson, J. H.; Sono, M. Chem. Rev. 1987, 87, 1255-1276.

(13) Sono, M.; Roach, M. P.; Coulter, E. D.; Dawson, J. H. Chem. Rev. 1996, 96, 2841-2888.

(14) Denisov, I. G.; Makris, T. M.; Sligar, S. G.; Schlichting, I. Chem. Rev. 2005, 105, 2253-2278.

(15) Xie, S.-X.; Kato, Y.; Komeda, H.; Yoshida, S.; Asano, Y. Biochemistry 2003, 42, 12056.

(16) Pedras, M. S. C.; Montaut, S. Bioorg. Med. Chem. 2003, 11, 31153120.

(17) Pedras, M. S. C.; Minic, Z.; Thongbam, P. D.; Bhaskar, V.; Montaut, S. Phytochem. 2010, 71, 1952-1962.

(18) Xie, S.-X.; Kato, Y.; Asano, Y. Biosci. Biotechnol. Biochem. 2001, 65, 2666-2672.

(19) Oinuma, K.-I.; Hashimoto, Y.; Konishi, K.; Goda, M.; Noguchi, T.; Higashibata, H.; Kobayashi, M. J. Biol. Chem. 2003, 278, 2960029608.

(20) Kato, Y.; Yoshida, S.; Xie, S.-X.; Asano, Y. J. Biosci. Bioeng. 2004, 97, 250-259.

(21) Kato, Y.; Asano, Y. Biosci. Biotechnol. Biochem. 2005, 69, 22542257.

(22) Kato, Y.; Asano, Y. Appl. Microbiol. Biotechnol. 2006, 70, 92-101.

(23) Sawai, H.; Sugimoto, H.; Kato, Y.; Asano, Y.; Shiro, Y.; Aono, S. J. Biol. Chem. 2009, 284, 32089-32096.

(24) Konishi, K.; Ishida, K.; Oinuma, K.-I.; Ohta, T.; Hashimoto, Y.; Higashibata, H.; Kitagawa, T.; Kobayashi, M. J. Biol. Chem. 2004, 279, 47619-47625.

(25) Boucher, J.-L.; Delaforge, M.; Mansuy, D. Biochemistry 1994, 33, $7811-7818$

(26) Hart-Davis, J.; Battioni, P.; Boucher, J.-L.; Mansuy, D. J. Am. Chem. Soc. 1998, 120, 12524-12530.

(27) Lefevre-Groboillot, D.; Dijols, S.; Boucher, J.-L.; Mahy, J.-P.; Ricoux, R.; Desbois, A.; Zimmermann, J.-L.; Mansuy, D. Biochemistry 2001, 40, 9909-9917.

(28) Wang, C. C.-Y.; Ho, D. M.; Groves, J. T. J. Am. Chem. Soc. 1999, 121, 12094-12103.

(29) Oinuma, K.-I.; Ohta, T.; Konishi, K.; Hashimoto, Y.; Higashibata, H.; Kitagawa, T.; Kobayashi, M. FEBS Lett. 2004, 568, 44-48.

(30) Kobayashi, K.; Yoshioka, S.; Kato, Y.; Asano, Y.; Aono, S. J. Biol. Chem. 2005, 280, 5486-5490.

(31) Oinuma, K.-I.; Kumita, H.; Ohta, T.; Konishi, K.; Hashimoto, Y.; Higashibata, H.; Kitagawa, T.; Shiro, Y.; Kobayashi, M. FEBS Lett. 2005, 579, 1394-1398.

(32) Konishi, K.; Ohta, T.; Oinuma, K.-I.; Hashimoto, Y.; Kitagawa, T.; Kobayashi, M. Proc. Natl. Acad. Sci. U.S.A. 2005, 103, 564-568.

(33) Kobayashi, K.; Kubo, M.; Yoshioka, S.; Kitagawa, T.; Kato, Y.; Asano, Y.; Aono, S. ChemBioChem 2006, 7, 2004-2009.

(34) Kobayashi, K.; Pal, B.; Yoshioka, S.; Kato, Y.; Asano, Y.; Kitagawa, T.; Aono, S. J. Inorg. Biochem. 2006, 100, 1069-1074.

(35) Pinakoulaki, E.; Koutsouppakis, K.; Sawai, H.; Pavlou, A.; Kato, Y.; Asano, Y.; Aono, S. J. Phys. Chem. B 2011, 115, 13012-13018.

(36) Pinakoulaki, E.; Gemeinhardt, S.; Saraste, M.; Varotsis, C. J. Biol. Chem. 2002, 277, 23407-23413.

(37) Linder, D. P.; Rodgers, K. R.; Banister, J.; Wyllie, G. R. A.; Ellison, M. K.; Scheidt, W. R. J. Am. Chem. Soc. 2004, 126, 14136-14148. 
(38) Praneeth, V. K. K.; Paulat, F.; Berto, T. C.; George, S. D.; Näther, C.; Sulok, C, D.; Lehnert, N. J. Am. Chem. Soc. 2008, 130, 15288-15303.

(39) Soldatova, A. V.; Ibrahim, M.; Olson, J. S.; Czernuszewicz, R. S.; Spiro, T. G. J. Am. Chem. Soc. 2010, 132, 4614-4625.

(40) Lanucara, F.; Chiavarino, B.; Crestoni, M. E.; Scuderi, D.; Sinha, R. K.; Maître, P.; Fornarini, S. Inorg. Chem. 2011, 50, 4445-4452.

(41) Pan, X.-L.; Cui, F.-C.; Liu, W.; Liu, J.-Y.J. Phys. Chem. B 2012, 116, $5689-5693$.

(42) Schröder, D.; Shaik, S.; Schwarz, H. Acc. Chem. Res. 2000, 33, 139-145.

(43) Shaik, S.; Hirao, H.; Kumar, D. Acc. Chem. Res. 2007, 40, 532542.

(44) Shaik, S.; Kumar, D.; de Visser, S. P.; Altun, A.; Thiel, W. Chem. Rev. 2005, 105, 2279-2328.

(45) Shaik, S.; Cohen, S.; Wang, Y.; Chen, H.; Kumar, D.; Thiel, W. Chem. Rev. 2010, 110, 949-1017.

(46) Olsson, M. H. M.; Søndergaard, C. R.; Rostkowski, M.; Jensen, J. H. J. Chem. Theory Comput. 2011, 7, 525-537.

(47) MacKerell, A. D., Jr.; Bashford, D.; Bellott, M.; Dunbrack, R. L., Jr.; Evanseck, J.; Field, M. J.; Fischer, S.; Gao, J.; Guo, H.; Ha, S.; et al. J. Phys. Chem. B 1998, 102, 3586-3616.

(48) Brooks, B. R.; Bruccoleri, R. E.; Olafson, B. D.; States, D. J.; Swaminathan, S.; Karplus, M. J. Comput. Chem. 1983, 4, 187-217.

(49) Sherwood, P.; de Vries, A. H.; Guest, M. F.; Schreckenbach, G.; Catlow, C. R. A.; French, S. A.; Sokol, A. A.; Bromley, S. T.; Thiel, W.; Turner, A. J.; et al. J. Mol. Struct. (THEOCHEM) 2003, 632, 1-28.

(50) Chemshell, a Computational Chemistry Shell; Science \& Technology Facilities Council: Swindon, UK; www.chemshell.org. (Accessed July 9, 2012).

(51) Ahlrichs, R.; Bär, M.; Häser, M.; Horn, H.; Kölmel, C. Chem. Phys. Lett. 1989, 162, 165-169.

(52) Smith, W.; Forester, T. R. J. Mol. Graph. 1996, 14, 136-141.

(53) Becke, A. D. J. Chem. Phys. 1993, 98, 5648-5652.

(54) Lee, C.; Yang, W.; Parr, R. G. Phys. Rev. B 1988, 37, 785-789.

(55) Roy, L. E.; Hay, P. J.; Martin, R. L. J. Chem. Theory Comput. 2008, 4, 1029-1031.

(56) Weigend, F.; Ahlrichs, R. Phys. Chem. Chem. Phys. 2005, 7, 32973305.

(57) Grimme, S. J. Comput. Chem. 2006, 27, 1787-1799.

(58) Baker, J. J. Comput. Chem. 1986, 7, 385-395.

(59) Frisch, M. J.; Trucks, G. W.; Schlegel, H. B.; Scuseria, G. E.; Robb, M. A.; Cheeseman, J. R.; Scalmani, G.; Barone, V.; Mennucci, B.; Petersson, G. A. et al. Gaussian 09, Revision B.01; Gaussian, Inc.: Wallingford, CT, 2009.

(60) Siegbahn, P. E. M.; Blomberg, M. R. A. Chem. Rev. 2000, 100, 421-437.

(61) Siegbahn, P. E. M.; Himo, F. J. Biol. Inorg. Chem. 2009, 14, 643651.

(62) Siegbahn, P. E. M.; Himo, F. WIREs Comput. Mol. Sci. 2011, 1, $323-336$.

(63) Marenich, A. V.; Cramer, C. J.; Truhlar, D. G. J. Phys. Chem. B 2009, 113, 6378-6396.

(64) Gonzalez, C.; Schlegel, H. B. J. Chem. Phys. 1989, 90, 2154-2161.

(65) Gonzalez, C.; Schlegel, H. B. J. Phys. Chem. 1990, 94, 5523-5527.

(66) Kolandaivel, P.; Senthilkumar, K. J. Mol. Struct. (THEOCHEM)

2001, 535, 61-70.

(67) Ellin, R. I.; Carlese, J. S.; Kondritzer, A. A. J. Pharm. Sci. 1962, 51, 141-146.

(68) Ogliaro, F.; de Visser, S. P.; Cohen, S.; Sharma, P. K.; Shaik, S. J. Am. Chem. Soc. 2002, 124, 2806-2817.

(69) de Visser, S. P.; Shaik, S. J. Am. Chem. Soc. 2003, 125, 7413-7424. (70) Schöneboom, J. C.; Thiel, W. J. Phys. Chem. B 2004, 108, 74687478.

(71) Bach, R. D.; Dmitrenko, O. J. Am. Chem. Soc. 2006, 128, 14741488.

(72) Usharani, D.; Zazza, C.; Lai, W.; Chourasia, M.; Waskell, L.; Shaik, S. J. Am. Chem. Soc. 2012, 134, 4053-4056.

(73) Lonsdale, R.; Harvey, J. N.; Mulholland, A. J. J. Phys. Chem. Lett. 2010, 1, 3232-3237.
(74) Lai, W.; Shaik, S. J. Am. Chem. Soc. 2011, 133, 5444-5452.

(75) Schyman, P.; Lai, W.; Chen, H.; Wang, Y.; Shaik, S. J. Am. Chem. Soc. 2011, 133, 7977-7984.

(76) Kumar, D.; Thiel, W.; de Visser, S. P. J. Am. Chem. Soc. 2011, 133, 3869-3882.

(77) Polyak, I.; Reetz, M. T.; Thiel, W. J. Am. Chem. Soc. 2012, 134, 2732-2741.

(78) Liao, R.-Z.; Thiel, W. J. Chem. Theory Comput. 2012, DOI: $10.1021 / \mathrm{ct} 3000684$.

(79) Richter-Addo, G. B.; Wheeler, R. A.; Hixson, C. A.; Chen, L.; Khan, M. A.; Ellison, M. K.; Schulz, C. E.; Scheidt, W. R. J. Am. Chem. Soc. 2001, 123, 6314-6326.

(80) Serres, R. G.; Grapperhaus, C. A.; Bothe, E.; Bill, E.; Weyhermüller, T.; Neese, F.; Weighardt, K. J. Am. Chem. Soc. 2004, $126,5138-5153$.

(81) Lanucara, F.; Chiavarino, B.; Crestoni, M. E.; Scuderi, D.; Sinha, R. K.; Maître, P.; Fornarini, S. Inorg. Chem. 2011, 50, 4445-4452.

(82) Wyllie, G. R. A.; Scheidt, W. R. Chem. Rev. 2002, 102, 1067-1089.

(83) Paulat, F.; Lehnert, N. Inorg. Chem. 2007, 46, 1547-1549.

(84) Brown, S. D.; Peters, J. C. J. Am. Chem. Soc. 2005, 127, 19131923.

(85) Bart, S. C.; Lobkovsky, E.; Bill, E.; Chirik, P. J. J. Am. Chem. Soc. 2006, 128, 5302-5303.

(86) Klinker, E. J.; Jackson, T. A.; Jensen, M. P.; Stubna, A.; Juhász, G.; Bominaar, E. L.; Münck, E.; Que, L., Jr. Angew. Chem., Int. Ed. 2006, 45, 7394-7397.

(87) Klotz, K. L.; Slominski, L. M.; Riemer, M. E.; Phillips, J. A.; Halfen, J. A. Inorg. Chem. 2009, 48, 801-803.

(88) Conradie, J.; Ghosh, A. Inorg. Chem. 2010, 49, 243-248.

(89) King, E. R.; Hennessy, E. T.; Betley, T. A. J. Am. Chem. Soc. 2011, 133, 4917-4923.

(90) Einsle, O.; Messerschmidt, A.; Huber, R.; Kroneck, P. M. H.; Neese, F. J. Am. Chem. Soc. 2002, 124, 11737-11745.

(91) Martí, M. A.; Crespo, A.; Bari, S. E.; Doctorovich, F. A.; Estrin, D. A. J. Phys. Chem. B 2004, 108, 18073-18080.

(92) Bykov, D.; Neese, F. J. Biol. Inorg. Chem. 2011, 16, 417-430.

(93) Wirstam, M.; Blomberg, M. R. A.; Siegbahn, P. E. M. J. Am. Chem. Soc. 1999, 121, 10178-10185.

(94) Guallar, V.; Friesner, R. A. J. Am. Chem. Soc. 2004, 126, 85018508.

(95) Kumar, D.; Hirao, H.; de Visser, S. P.; Zheng, J.; Wang, D.; Thiel, W.; Shaik, S. J. Phys. Chem. B 2005, 109, 19946-19951.

(96) Kamachi, T.; Yoshizawa, K. J. Am. Chem. Soc. 2005, 127, 1068610692.

(97) Zheng, J.; Wang, D.; Thiel, W.; Shaik, S. J. Am. Chem. Soc. 2006, 128, 13204-13215.

(98) Cho, K.-B.; Derat, E.; Shaik, S. J. Am. Chem. Soc. 2007, 129, 31823188.

(99) Chung, L. W.; Li, X.; Sugimoto, H.; Shiro, Y.; Morokuma, K. J. Am. Chem. Soc. 2008, 130, 12299-12309.

(100) Chen, H.; Moreau, Y.; Derat, E.; Shaik, S. J. Am. Chem. Soc. 2008, 130, 1953-1965.

(101) Robinet, J. J.; Cho, K.-B.; Gauld, J. W. J. Am. Chem. Soc. 2008, $130,3328-3334$.

(102) Altarsha, M.; Benighaus, T.; Kumar, D.; Thiel, W. J. Am. Chem. Soc. 2009, 131, 4755-4763.

(103) Chung, L. W.; Li, X.; Sugimoto, H.; Shiro, Y.; Morokuma, K. J. Am. Chem. Soc. 2010, 132, 11993-12005.

(104) Lai, W.; Chen, H.; Matsui, T.; Omori, K.; Unno, M.; Ikeda-Saito, M.; Shaik, S. J. Am. Chem. Soc. 2010, 132, 12960-12970.

(105) Yanai, T. K.; Mori, S. Chem. Asian. J. 2008, 3, 1900-1911.

(106) Yanai, T. K.; Mori, S. Chem.-Eur. J. 2009, 15, 4464-4473.

(107) Cho, K.-B.; Lai, W.; Hamberg, M.; Raman, C. S.; Shaik, S. Arch. Biochem. Biophys. 2011, 507, 14-25.

(108) He, B.; Sinclair, R.; Copeland, B. R.; Makino, R.; Powers, L. S.; Yamazaki, I. Biochemistry 1996, 35, 2413-2420.

(109) Lloyd, E.; Burk, D. L.; Ferrer, J. C.; Maurus, R.; Doran, J.; Carey, P. R.; Brayer, G. D.; Mauk, A. G. Biochemistry 1996, 35, 11901-11912. 
(110) Hopmann, K. H.; Himo, F. Eur. J. Inorg. Chem. 2008, No. 9, 1406-1412. 